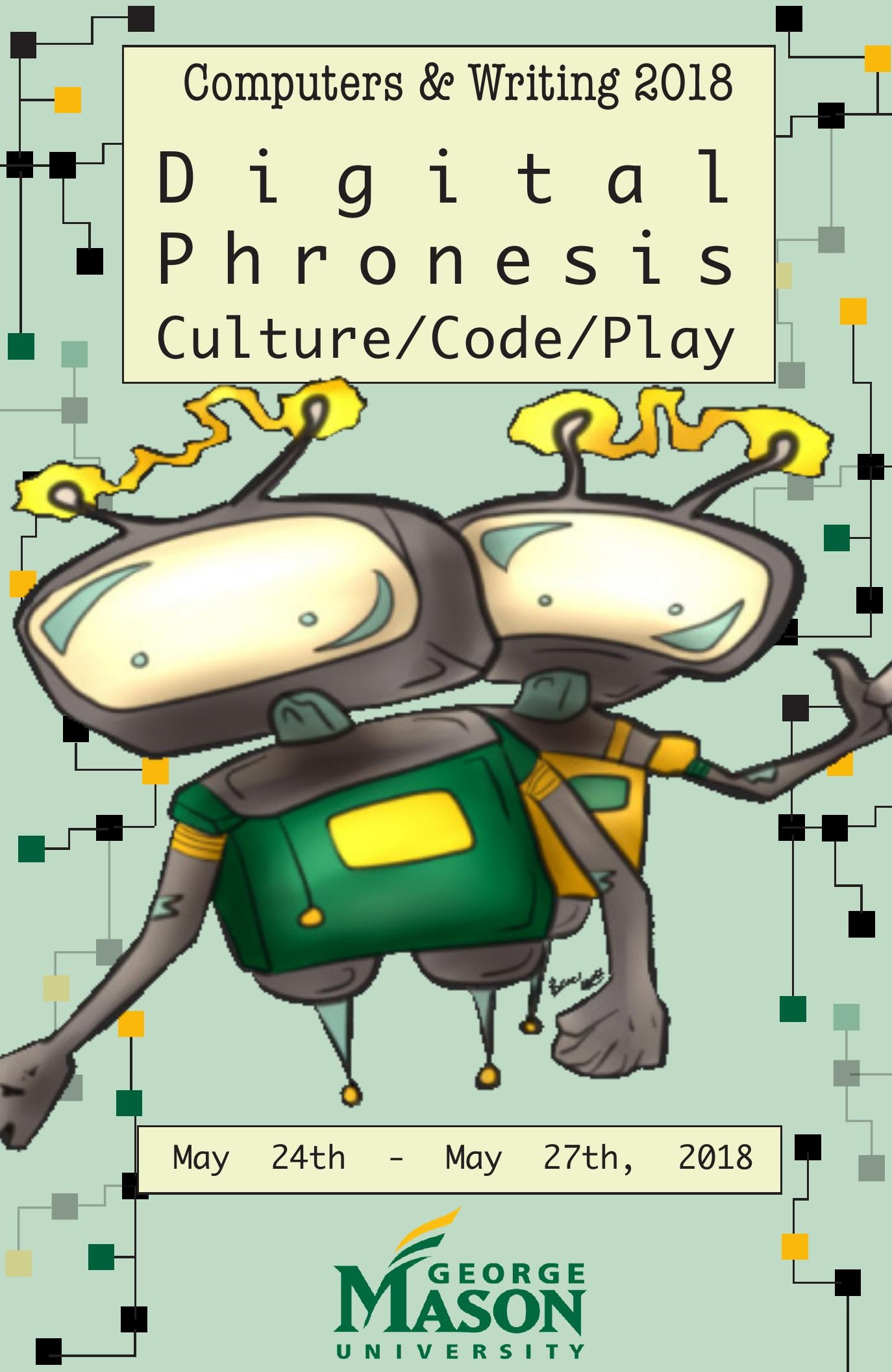





\section{Digital Phronesis: \\ Culture/Code/Play}

May 24-May 27 2018, George Mason University 4400 University Drive, Fairfax, VA 22030

\section{Table of Contents}

Welcome Letter

Schedule at a Glance

Conference Information

Connecting to Mason WiFi

Campus Maps

Local Food \& Drink

Activity \& Session Descriptions

Thursday May 24th

Friday May 25th

Saturday May 26th

44

Sunday May 27th

71

Conference Reviewers

82

Special Thanks

83

Conference Volunteers

84

Conference Sponsors

85

Participant Index

86 


\section{Welcome to Mason!}

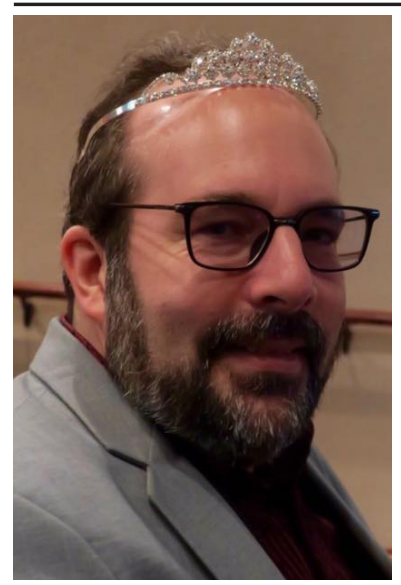

On behalf of the Writing and Rhetoric programs at GMU, the department of English, the University Libraries, and the conference planning committee, I am delighted to welcome you to Mason for the 34th Computers and Writing Conference. Our goal is to bring together our scholars, students, and community members to continue our exploration

writing, computers, (both defined quite broadly) and the possibilities and challenges of brining these technologies together.

Our aim this year is to provide an exhiliarting and accessible conference, and as I worked on the program I found that I wanted to attend *all* of the sessions. I hope that you will find the offerings equally engaging and exciting.

I want to particularly thank a few people who were instrumental in putting on the show this year:

Jen Ware and Ashley Hall once again provided excellent support with the C\&W website; Matt Green served as our coordinator of volunteers; Beth Caravella designed the "happy robots" logo and program layout; and Rachael Lussos contributed both design expertise (those great boxes!) and also an excess of logistical support and organizational skill.

Here's to you, Computers and Writing \#34!

Douglas Eyman, 2018 C\&W Conference Chair

2| Welcome Letter 


\section{Schedule At A Glance}

\section{Thursday May 24th}

\begin{tabular}{|l|l|}
\hline 9:00 am - 12:00 pm & $\begin{array}{l}\text { Morning Workshop Sessions (Fenwick \& } \\
\text { Johnson Center) }\end{array}$ \\
\hline 12:00 pm - 1:00 pm & Lunch @ The MIX \\
\hline 1:00 pm - 4:00 pm & $\begin{array}{l}\text { Afternoon Workshop Sessions (Fenwick \& } \\
\text { Johnson Center) }\end{array}$ \\
\hline 5:00 pm - 7:00 pm & $\begin{array}{l}\text { Opening Reception \& Digital Showcase @ } \\
\text { The MIX }\end{array}$ \\
\hline
\end{tabular}

\section{Friday May 25th}

\begin{tabular}{|l|l|}
\hline 9:00 am - 10:15 am & Concurrent Sessions A (Fenwick \& JC) \\
\hline 10:30 am - 11:45 am & Concurrent Sessions B (Fenwick \& JC) \\
\hline 12:00 pm - 2:00 pm & Keynote \& Lunch (Dewberry/Bistro, JC) \\
\hline 2:15 pm - 3:30 pm & Concurrent Sessions C (Fenwick \& JC) \\
\hline 3:45 pm - 5:00 pm & Concurrent Sessions D (Fenwick \& JC) \\
\hline 6:00 pm - 8:00 pm & Awards Banquet (Dewberry/Bistro, JC) \\
\hline 8:30 pm - 11:30 pm & Bowling! \\
\hline Saturday May 26th \\
\hline
\end{tabular}

\begin{tabular}{|l|l|}
\hline 9:00 am - 10:15 am & Concurrent Sessions E (Fenwick \& JC) \\
\hline 10:30 am - 11:45 am & Concurrent Sessions F (Fenwick \& JC) \\
\hline 12:00 pm - 2:00 pm & Keynote \& Lunch (Dewberry/Bistro, JC) \\
\hline 2:15 pm - 3:30 pm & Concurrent Sessions G (Fenwick \& JC) \\
\hline 3:45 pm - 5:00 pm & Concurrent Sessions H (Fenwick \& JC) \\
\hline 5:15 pm - 6:30 pm & Poster Session \\
\hline Sunday May 27th & \multicolumn{2}{|l}{} \\
\hline 9:00 am - 10:15 am & Concurrent Sessions I (Fenwick \& JC) \\
\hline 10:30 am - 11:45 am & Concurrent Sessions J (Fenwick \& JC) \\
\hline 12:00 pm - 1:00 pm & Lunch \& 7C Meeting (JC-Dewberry) \\
\hline
\end{tabular}




\section{Conference Information}

\section{Registration \& Help Desk}

On Thursday, the Registration Desk will be located in the MIX; Friday-Sunday Registration will be in the Dewberry Hall lobby, on the bottom level of the Johnson Center (JC). Our volunteers are happy to help and answer questions; just let us know if you need assistance.

\section{Exhibitors}

Exhibitors are located in on the third floor of the Johnson Center, Friday-Sunday. Coffee breaks will also be served in this area on Friday and Saturday from 3-4pm. Exhibitor's hours will be from 9am to $5 \mathrm{pm}$ on Friday and Saturday, with optional hours on Sunday from 9am to noon.

\section{Parking}

Free parking for the conference is available in the Rappahanock River Parking Deck on levels one and two of the general parking area (do not park in the visitor parking area - look for "C\&W Parking" signs). No pass is required.

\section{Anti-Harassment Policy}

All confernece attendees agree to create a safe atmosphere both during conference events and after hours on campus, in housing, and around town. Harassment based on gender, sexuality, race, size, ability, or age is strictly prohibited. Concerns should be directed to the Registration desk, or to one of the conference ambassadors staying in the dorms. 


\section{Photo/Video Policy}

We have not arranged for photography or videography at the conference, but participants are encouraged to share photos and videos via the \#cwcon and \#cwcon18 hashtags. Please be considerate of your colleagues in attendance and be sure to obtain permission from anyone who is identifiable/in focus before posting.

\section{Fragrance-Free Request}

In order to ensure that all of our participants feel welcomed and supported, we respectfully request that attendees not use scented personal products (such as fragrances, colognes, and lotions) while attending the conference.

\section{Quiet Room}

Fenwick 5003 is our designated quiet room, but it is also used as a quiet reading room by the library community at large.

\section{Mason Wi-Fi}

1. On your device, select MASON as your wireless network

2. Go to your Web browser and enter itsservices.gmu.edu

3. The self-registration portal will appear

4. Click on Create an Account and enter your information to complete self-registration

The authentication system will assign a username and password. Guests can also connect to the wired network via active jacks in the residence halls, classrooms, and public areas around campus. 


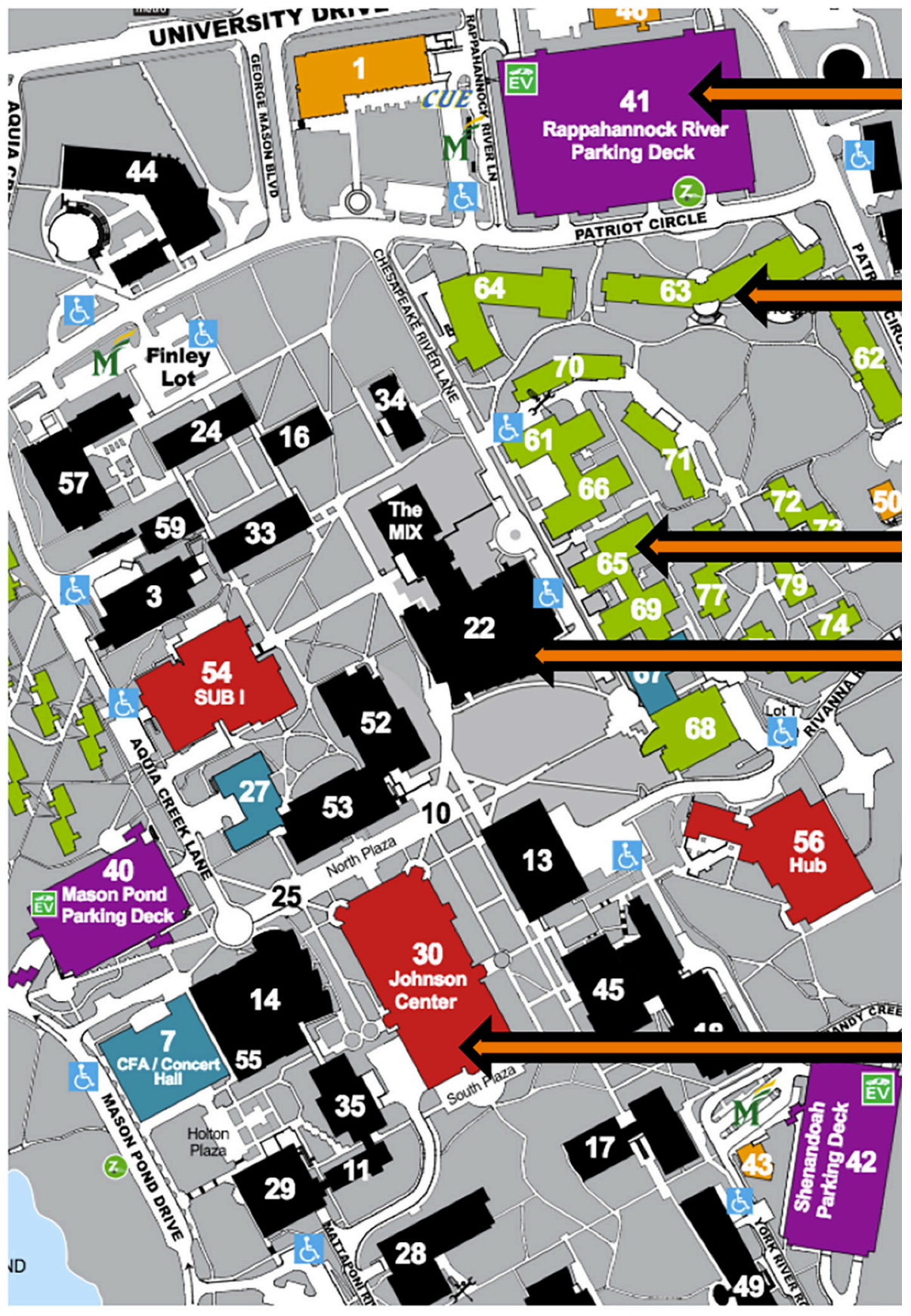

6 | Campus Maps: Parking and Main Conference Buildings 


\section{Rappahanock River Parking Deck - C\&W Parking}

63. Hampton Roads Conference Dorms

65. Piedmont Hall - Pick Up Dorm Keycard Here

22. Fenwick Library and The MIX - GRN, Thursday Registration and workshops; Fri-Sun sessions in Fenwick

30. Johnson Center (the JC)

- Fri-Sun Registration, sessions, posters, keynotes, and banquet 


\section{JC, ground floor}

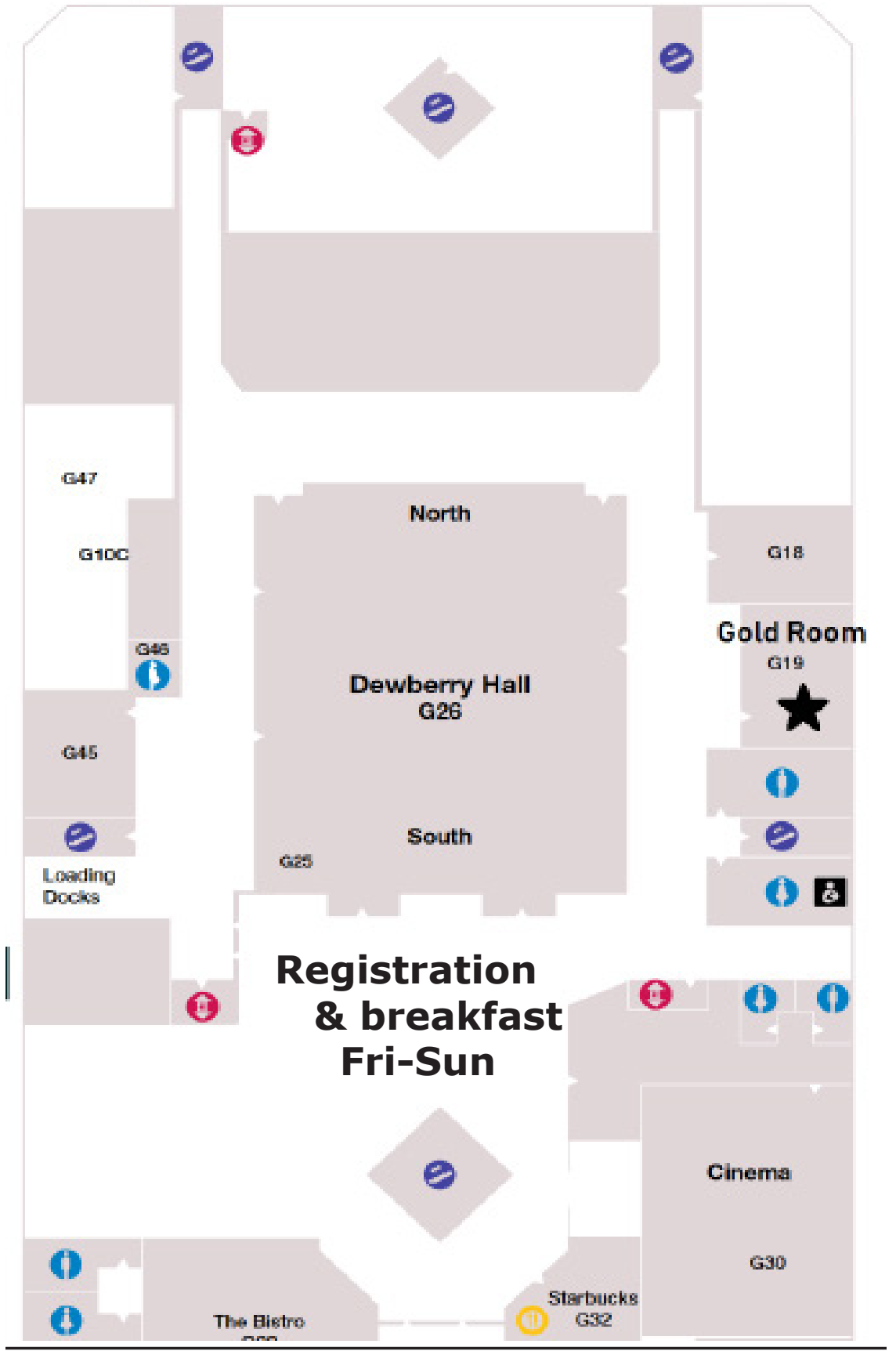

8 | Campus Maps: Johnson Center 


\section{JC, third floor}

C $200 \mathrm{H}$

$\frac{c^{6}}{323}$

$B 3 x \mathrm{~A}$
(i]
c)

39

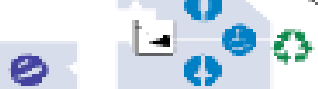

\section{Ltwary}

stocks

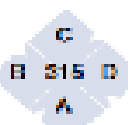

Lterany

stocks
George's

3214 the 321
9

Student Centers 324
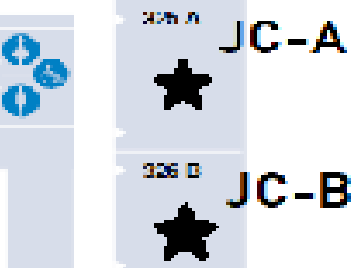

yai JC-C

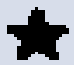

xys

e 6 줄

$x \rightarrow 4$

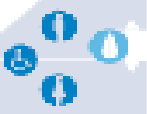

$x \times-$

344

345

34

541

ase F JC-F

340

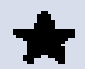

$93:$ JC-G

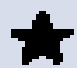




\section{Fenwick, first floor}

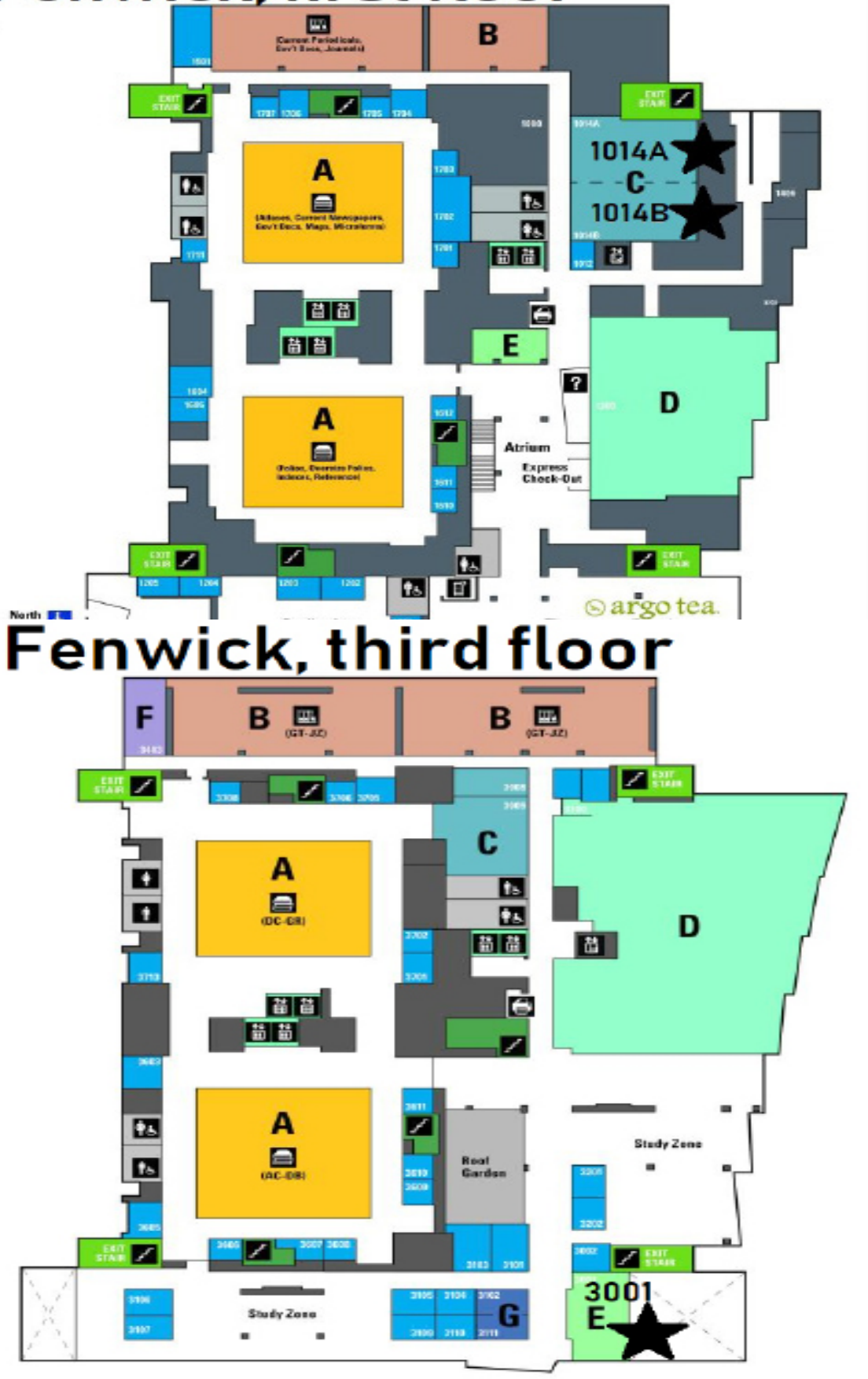




\section{Fenwick, fourth floor}

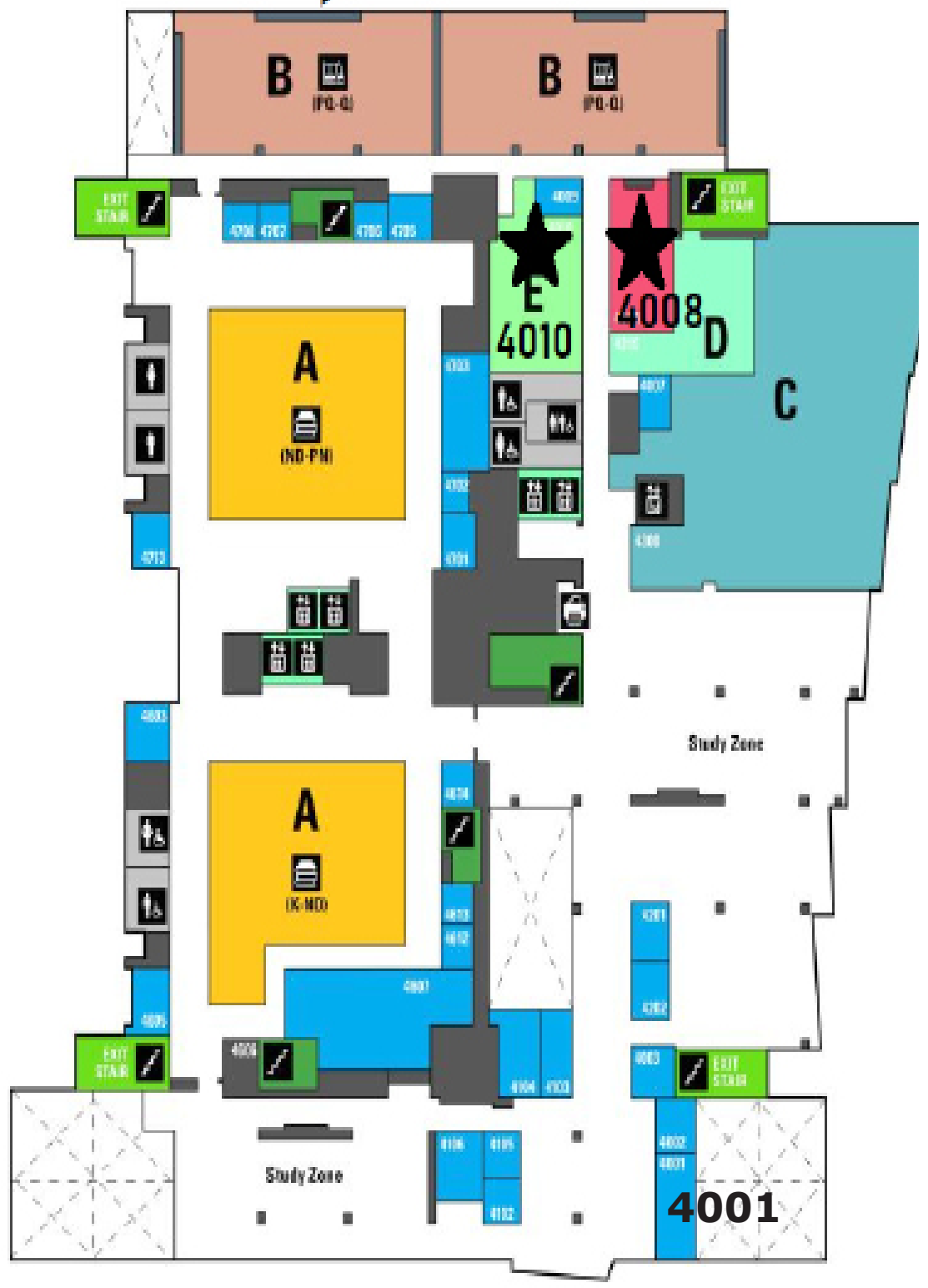




\section{Local Food \& Drink}

Here are some of the conference planning committee's local favorite spots for food and drink around Fairfax. We'll post a larger list of crowdsourced recommendations to the conference website (http://candwcon.org/2018/dining)

\section{On Campus}

Argo Tea in the lobby of Fenwick Library will be open 8-4 on Thursday and Friday.

\section{University Mall}

University Mall is just south of campus on the other side of Braddock Road. The main watering hole for faculty is Oh George! - Fat Tuesday is a dive bar, and there is also a decent grocery store (Giant).

\section{Downtown Fairfax}

Downtown Fairfax is about a mile from campus and is a 20 minute walk--just followUniversity Blvd north. All of these restaurants are in a three block area downtown:

21 Great American Bistro - Upscale American

The Auld Shebeen - Irish Pub

Bollywood Bistro - Indian

Courtyard Thai - Thai

EastWind - Vietnamese/Pho

Eerkin's Uyghur Cuisine - Uyghur/Chinese/Turkish

French Quarter Brasserie - New Orleans

High Side - Craft Beer \& Asian Street Food

Hamrock's - American

Natalie's Baguette - French

Sister's Thai - Thai

The Wine House - Upscale American

12 | Local Food \& Drink 


\section{Pre-Conference Workshops Thursday, May 24th}

\section{Graduate Research Network}

The Mix | 9:00 am - 4:00 pm

Janice Walker \& Angela Haas

Roundtable discussions provide an ideal setting share research with colleagues of similar interests. Coversations are facilitated by discussion leaders and work at any stage of completion, from conceptualization to publication, is welcome.

Note: Please see GRN Program for a detailed list of events.

\section{Morning Workshops}

\section{MW.1 A-Call to Action:-Bigital-Rhetoric with Nonprofits-(Canceled)-}

Fenwick 1014A | 9:00 am - 12:00 pm

Aimée Knight, John J. Silvestro, Bill Wolff

This workshop features several models to involve academic courses with local nonprofits and community-based organizations via digital projects. Workshop participants are guided through the process of designing and developing their own project or assignment that responds to community-identified needs.

\section{MW.2 PhronesisM00:-A-Comptters \& Writing Conference-Greative-Community-(Canceled)}

Fenwick 1014B | 9:00 am - 12:00 pm

Kristopher Purzycki \& Geoffrey Gimse

Following in the footsteps of past community spaces such as the Technorhetoric Bar and Grill on MediaMOO and Haynes and Holmevik's LinguaMOO, this workshop will focus on creating PhronesisMOO, a new multi-user domain (MUD) to be released to the C\&W community. 


\section{MW.3 Creating 3D Games with the (Free, Open- source) Blender Game Engine}

Fenwick 4010 | 9:00 am - 12:00 pm

Dennis Jerz

Using the free, open-source Blender Game Engine, participants will alter the default mechanics of simple arcade and maze games into an explicitly rhetorical digital artifact in order to examine the pedagogically useful ways this exercise can provide students with rhetorical mindfulness.

\section{MW.4 Creating/Revising Digital Project Assignments to Facilitate Writing Transfer}

Fenwick 3001 | 9:00 am - 12:00 pm

Crystal Fodrey \& Meg Mikovits

This workshop explores the relationship between multimodal, digital assignments and teaching for transfer. Participants are asked to come prepared with a current or potential multimodal assignment that they will work with to collaboratively (re)envision assignments to incorporate transfer-facilitating practices.

\section{MW.5 Evocative Objects Workshop:}

Re-imagining the Possibilities of Material

Objects and Multimodal Composing

Fenwick 1014B | 9:00 am - 12:00 pm

Jody Shipka \& Jason Markins

By composing complex 3D (analog) object-texts, participants can re-frame the tendency in the field to associate multimodality with digital media or visual-verbal 2D object-texts. By doing so, participants challenge the assumption that these 3D object-texts are arhetorical or purely expressive instead of valuable scholarly, academic artefacts. 


\section{Afternoon Workshops}

\section{AW.1 Learning Aurasma (Augmented Reality App) to Engage with Place, Play, and Practice}

Fenwick 1014A | 1:00 pm - 4:00 pm

April Conway \& Thomas Javier Castillo

Participants will work with augmented reality (AR) software (Aurasma) to create site-specific multimedia compositions. Participants should bring an iOS or Android phone or connected device and should plan to download the Aurasma AR app beforehand.

\section{AW.2 Building User-Experience (UX) Research Centers}

Fenwick 4010 | 1:00 pm - 4:00 pm

Laura Gonzales, Ann Shivers-McNair, Candice Lanius, Joy Robinson

Workshop leaders explore the role that user-experience (UX) research centers can play in a university setting. Participants discuss the practicalities of developing UX research centers on campus in order to promote relationships between these centers and universities, communities, and industries.

\section{AW.3 Sparking Creativity: Digital Literacies for Your Invention-Based Composition Course}

Fenwick 1014B | 1:00 pm - 4:00 pm

Jan Rune Holmevik, Amy Patterson, Chelsea Slack, Eric Hamilton, Shauna Chung, Shelly Lloyd, Victoria Houser

Participants receive hands-on experience with Adobe Spark and Behance, learning how to use these creative tools to transform their composition courses into unique invention-based learning experiences. 


\section{AW.4 Weaving Nonlinear Tales: Constructing Ludic Narratives with Twine 2.x}

Fenwick 4008 | 1:00 pm - 4:00 pm

Anastasia Salter, Eric Murnane, Laura Moeller

Participants learn techniques for crafting nonlinear experiences using Twine, a beginner-friendly platform for creating interative narrative games with an emphasis on translating design patterns into play. Participants are encouraged to bring a Mac or PC to complete their designs.

\section{AW.5 Zork's Revenge: The Return of Interactive Texts to Writing Courses}

Fenwick 4008 1 1:00 pm - 4:00 pm

Daniel Frank, Christopher Wyatt, Lauren Woolbright, Daniel Cox

Through playing examples of interactive fiction games and then learning how to use the tools to make them, participants create a basic interactive work, learning strategies for incorporating interactive fiction in assignments and curriculum for their own courses and writing programs.

\section{NB: AW.4 and AW.5 Have Joined Forces and will both be in Fenwick 4008.}




\section{Opening Reception \& Digital Project Showcase}

The MIX | 5:00 pm - 7:00 pm

Enjoy hors d'ouvres and libations along with a showcase of projects developed at the first KairosCamp (summer 2017).

Douglas Eyman, Showcase Chair

Erin Kathleen Bahl, Refracting Webtexts: Invention and Design in Composing Multimodal Scholarship

Chen Chen, \#FOMO: Visualizing Disciplinary Lore on WPA-L

Patricia Fancher, Practice and Progress: Visualizing Community in America's Early Female Physicians

David Hochfelder, 40 Blocks, Thousands of Stories: Digitally Narrating Urban Renewal

Jen Justice \& Wendi Sierra, Designing Scholarship:

GradLife the RPG

Ben McCorkle \& Jason Palmeri, Teaching with Television in English Journal Archives

Will Penman, Siri's Identity: How People on the Margins Use Parody YouTube Videos to Make Themselves Represented in AI

Mary P. Sheridan, Making Future Matters

Sarah Welsh, Delete this Article: Screenshots, Archives, and Digital Forgetting 


\section{Concurrent Session A Friday, May 25th 9:00 am - 10:15 am}

\section{A.1 Playing with Multimodality in the Comp Classroom: An Assignment to Get the Process Started}

Fenwick 1014B | Mini-Workshop Dawn Mellinger

This mini-workshop is for instructors who want to contemporize their college classroom instruction using computer technology but don't know how or where to begin. Participants will develop a multimodal assignment and rubric.

\section{A. 2 Adventures in Phronetic Spaces: Graduate Students \& Inter-institutional Horizontal Mentoring via Social Media Groups}

Johnson Center A | Roundtable Allegra Smith, Ashanka Kumari, Gavin Johnson, Christina Rowell, Kristie Ellison, Robin Farabedian

This roundtable reports and reflects on the horizontal mentoring experiences of participants in a PhD-student led Facebook group, including a content analysis of group posts that yields insights into the crowdsourcing practices, mentoring needs, networking opportunities, and knowledge circulation of participants.

\section{A.3 Research as Play: Promoting Inquiry through Pedagogies of Play}

JC-B | Roundtable

Trenia Napier, Courtnie Morin, Emily Hensley,

Rachel Winter

The ACRL Framework for Information Literacy for Higher Education (2016) sees information literacy as a metaliteracy organized around six threshold concepts; one of these concepts, Research as Inquiry, can be used to situate research in theories and pedagogies of play. 


\section{A4. Twitter, \#metoo, and Toxic Masculinity}

Fenwick 4010 | Panel

\#metoo: Resistance as a Mode of Attunement

Bryan Jones

The Risks and Opportunities of \# MeToo

Caroline Dadas

It Reeks Like a Boy's Locker Room: Twitter's Digital Aphorisms and Toxic Masculinity

Rory Lee

Bryan Jones uses Bakhtin's concept of the carnivalesque to show how \#metoo disrupts dominance through the violation of hierarchies; Caroline Dadas presents interview findings to show how marginalized populations use social media for consciousness-raising; and Rory Lee highlights the ways the tweet makes possible a digital manifestation of toxic masculinity.

\section{A.5 Emotions, Bodies, Embodiment}

Fenwick 3001 | Panel

Digital Composing (with) Bodies and Emotions:

Revisiting 'Deep Embodiment'

Rich Shivener

XM: Enacting the QueerOS

Abbie Levesque

Meeting Students Where They Are: Building Personalized Digital Assessment Tools

Andrew Famiglietti \& Robin Wharton

Rich Shivener argues for a deeper understanding of the practices and affective dimensions of digital scholarship; Abbie Levesque focuses on the implications of building a QueerOS in the form of an XML system for qualitative coding; and Andrew Famiglietti and Robin Wharton showcase software they developed to support their writing courses. 


\section{A.6 Cellphones and Selfies}

Fenwick 4008 | Panel

Reclaiming My Time: Selfies as Ekphrastic Hope Bonnie Kyburz

Writing for Mobile View: How Cellphones Encourage Students to Explore Metacognition and Flexibility

Catherine Forsa

Bonnie Kyburz describes selfies based on Mitchell's concept of "ekphrastic hope" and Catherine Forsa demonstrates how to foster flexibility and metacognition when students compose texts for cellphones' "mobile view."

\section{A.7 Gaming and First-Year Composition}

Fenwick 1014A | Panel

Using Video Games to Teach and Assess Audience and Revision in First-Year Composition

Kenton Howard

Harnessing Video Game Rhetoric

Greyson Sanders

The Game is Afoot: Learning to Play the Life of the Mind Philip Choong \& Sami Atassi

Kenton Howard shows a Composition I module he created based on the video game Organ Trail, a "retro zombie survival game"; Grayson Sanders explores the possibilities of video games as rhetoric, focusing on the "magic circle" of play; and Philip Choong and Sami Atassi describe their use of the social deduction game The Resistance in a composition course.

\section{A.8 "Always in the Process of Becoming": Phronesis in/as Writing Studies Research}

JC-C | Panel

Kelly Moreland, Lauren Garskie, Sara Austin

Located in their current research on TA preparation, feminist pedagogy, and informal writing spaces, the panelists share learning (and) experiences that shape our habits and values within both personal identities and research.

20 | Concurrent Session A 


\section{A.9 Creating a Culture of Accessible Teaching Practices}

\section{JC-D | Panel}

Kirstin Bone, Melissa Green, Sara Maurice Whitver

Drawing on tenets of Universal Design for Learning and Universal Design for Instruction (UDL/UDI), this panel offers three inter-related case studies for creating a culture of accessible learning practices both within and in support of the composition classroom.

\section{A.10 Methodology as Phronesis: Teaching and Learning Research as Embodied Practice JC-E | Panel}

How do I do Research, Again?: Phronetic Reflections on Co-teaching Methodology while Dissertating Julie Lindquist

Research Is Hard: Making the Visible the Embodied Work of Learning Methodology

Les Hutchinson

Learning to Learn, and Learn Again: Reflections on Methodology, Pedagogy, and Collaboration

Maria Novotny

This panel considers how to teach and learn methodology as a practice of phronesis: 1 ) as researchers at different moments in our careers (one grad student writing a dissertation, one post-dissertation, and one senior faculty person); and 2) as collaborators in the development and delivery of a graduate research methodology course.

\section{A.11 Planning for Change, Building in Redundancy: Preserving our C \&W Archives JC-F | Panel}

Ashley Hall, James Purdy, Jennifer Marlow, Michael Day, Naomi Silver (Chair)

This panel focuses on our Computers and Writing community's efforts to recover, reconstruct, and re-vision the online archive of its thirty-five years of historical artifacts. We will describe archive, note what has been recovered, and ask for suggestions for reconstruction. 


\section{A.12 Teaching Phronesis: Scaffolding Knowl- edge Application and Ethical Judgement in Digital Spaces JC-G | Panel}

The Bait and Switch: Covert Research Assignments and Skills Transfer

Casey McArdle

Playing to Learn: Immersive Learning and Applied Knowledge

Kate Birdsall

Joining the Conversation: Reflection and Presentation Kate Fedewa

Our exploration asks educators to help students develop and ethically apply "street smarts" as they work on projects in professional writing. Each speaker takes a specific verb as their focus, beginning with "research," moving through "play" and "transfer," and ending with "create."

\section{A.13 You're Using What to Teach What?! When Unconventional Pedagogical Methods Actually Work}

\section{JC-239 | Panel}

Memos, Messaging, and Mmmm, Brains!: An Apocalyptic Business Writing Course

Elkie Burnside

Hey What?! and HeLa: Race, Ethics, and Science Writing Pedagogy

Harley Ferris

From Anti-Suffrage Cartoons to Muslim Superheroines:

Teaching Feminism through Comics

Rachael Ryerson

When instructors stumble upon ideas "so crazy they just might work," students and teachers alike can experience unexpected gains that more traditional, accepted practices fail to yield. This panel explores three instances in which teachers applied gamification, creative non-fiction, and comics respectively to challenging undergraduate content with positive results. 


\section{A.14 Social Justice Working Group}

Johnson Center Gold Room | SIG

Kristin Arola, Samantha Blackmon, Kristine Blair, Angela Haas, Donnie Sackey, Emi Stuemke, Melanie Yergeau

The Social Justice Working Group seeks to foreground discussion of social justice in technology in order to build alliances while honoring differences. We extend special welcome to concerns and conversations surrounding the effects of schemes of normativity and tensions that arise along the axes of ability, identity, and access.

\section{A.UGRS Undergraduate Research Symposium}

George's @ the JC | Panel

Emoji's Effect on Digital Communication

Alexa Olah, Monmouth University

Brittany Cote, Monmouth University

Sarah Baker, Monmouth University

The increasing use of emojis, or small digital images used alongside or in place of text suggests that people are connecting to these images more personally than they are connecting with words alone. The panelists examine millennials' use of emojis and emojis' connection to millennials' unique childhoods, the similarity and representation of human facial features and expressions in emoji, and the role of visual communication, including emoji, infographics, concept maps, and infodoodles, in digital communication. 


\section{Concurrent Session B \\ Friday, May 25th \\ 10:30 am - 11:45 am}

\section{B.1 Facilitating Undergraduate Research in the Humanities through the "Continuous Course Lab"}

Fenwick 1014A | Mini-Workshop

Halcyon Lawrence, Sarah Lozier-Laiola

This workshop introduces the Continuous Course Lab $(\mathrm{CCL})$ model, which integrates long-form humanities research projects directly into the learning outcome, assessment, and structure of an undergraduate course.

\section{B.2 EnTwined Storytelling: Bringing Interactive Creative Nonfiction into the Classroom Fenwick 4010 | Mini-Workshop \\ Eric Murnane, Laura Moeller}

This mini-workshop invites participants to explore their own vulnerabilities by making interactive creative nonfiction using the open source tool Twine.

\section{B.3 Behind the Scenes of Digital Aggression Re- search: Identity, Method, Action, and Self-Care} JC-A | Roundtable

Erika Sparby, Katherine DeLuca, Kristine Blair, Rachael Sullivan, Samantha Blackmon, Stephanie Weaver

We ask, What happens when a researcher has chosen to research hostile spaces-particularly spaces that are hostile to her own identity/ies? Each speaker has experience with social media (including violent anti-woman discourses, political campaign imagery, and alt-right narratives); gaming, sexuality, and safety; and/or developing research strategies that include productive action as a key component. 


\section{B.4 Western Democracy, Social Media, and Trolls: Where to Start}

JC-B | Roundtable

Estee Beck, Liza Potts, Michael Trice, Douglas Walls

The 2016 election and the influence of both foreign powers and nonhuman composers have brought a series of challenges to western democracies. We discuss how digital rhetoricians and technical communicators must begin to leverage their expertise to understand and help shed light on these issues.

\section{B.5 Riding as Writing: How Cycling Allows New Writing(s)}

Fenwick 4008 | Panel

Bill Hart-Davidson, David Rieder, Drew Stowe, Lydia Wilkes

As digital technologies continue to develop they create new ways of creating meaning. By considering the ways that various technologies impact cycling we can also consider the ways that leisure, sport, health, and embodiment contribute to our ways of being in the world.

\section{B.6 Teaching Coding/Writing Code}

Fenwick 1014B | Panel

Pedacodegy: Toward Best Practices for Phronetic Coding Instruction in Postsecondary Education

Jim Nugent

Remediating Technologies, Remediating Writers: The Many Selves of Code-Writers Elisa Finlay

Jim Nugent addresses coding in postsecondary education; and Elisa Findlay presents a qualitative study regarding the construction and remediation of the writerly self. 


\section{B.7 "Fail Fast, Fail Often:" Perspectives on Risk-Taking from Agile Methodology to the Writing Classroom}

\section{JC-C | Panel}

Gamifying Experiences of Student "Failure" to Motivate Creativity and Innovation

Aaron Lanser

Teacher (Fear of) Failure: Teaching as Adaptation \& Problem Solving

Mary Stewart

Defining Student Failure: Student and Faculty

Perspectives on Digital Tools and Class Performance Jenae Cohn

This panel applies the Agile Methodology of "fail fast, fail often" to digital writing classrooms: how do we make experiences of failure playful and in what ways do we apply playful pedagogies to institutionalize an acceptance of failure as a part of learning?

\section{B.8 Multimodal Hip-Hop and Transforming Writ- ing Studies}

JC-E | Panel

Laquana Cooke, Regina Duthely, Todd Craig

Hip-hop's deployment of audio, alphabetic, and visual rhetorical strategies as an embodied composing practice should serve as a model for the radical possibilities of digital writing studies.

\section{B.9 Playing wtih Twitter: The Practical Wisdom of Social Media Reserach}

\section{JC-F | Panel}

Dan Anderson, Grant Glass, Desiree Dighton

This panel will consider how we might account for and reimagine the instability of data-based argument; how social media data relates with online and offline culture; and how this data might serve as an inventional resource for scholars, activists, and students. 


\section{B.10 Teaching Technology in Panem (or, How to Teach the Digital on an Analog Campus)}

JC-G | Panel

Ethics of Accessibility and Video Game Pedagogy

Jen Justice

Phones Are Technically Computers Now, Right?

Patricia Poblete

But Students Can Gust Go to the Library?

Tiffany Carter

While the panel enjoys and employs video games, social media, and multiple-media projects in class, we also look askance at the underlying technological assumptions often made in the composition classroom and will offer a number of possible multimedia projects that instructors can use regardless of the technology available.

\section{B.11 Both/And: Digital, Analog, and Physical Computing}

JC-239 | Panel

From Design Thinking to Design Doing: Phronesis in Maker Pedagogy

Jason Tham

Analog Poiesis Meets Digital Phronesis: Crafting Texts that Intentionally Blur the Lines between Digital and Analog Jason Markins

Understanding the Digital Through the Anti-Digital:

Letterpress in Writing Research and Teaching Devon Cook

In this panel, presenters re-evaluate the implications of design "thinking" and how we might theorize an improved, action-driven approach to innovation; discuss the materiality of composing circulation and the crafting of texts that intentionally blur the lines between digital and analog; and report on findings of a study of letterpress users composing practices with implications for research of writing via digital technologies. 


\section{B.12 Coding/Learning/Writing: A Cultural Digital Rhetorical Gathering}

JC Gold Room | Panel

Coding Land Relationality in Thunderbird Strike Elizabeth LaPensee

Learning Cherokee Online: Digital Survivance and Language Revitalization

Catheryn Jennings

Writing Culture: Powwow Bunnies and Rhetorical Velocity Kristin Arola

Interrogating the coding and design of the video game Thunderbird Strike, the ways one learns a heritage language through digital spaces, and one Ojibwe woman's attempt to rhetorically intervene in a social media attack on her cultural claims, this panel shows how cultural and digital rhetoric can, and should, intersect with our theories, pedagogies, and practices.

\section{B.13 Digital Archive of Literacy Narratives (DALN) Organizational Meeting}

Fenwick 3001 | Panel

Ben McCorkle \& Michael Harker

This organizational meeting, open to contributing partners, affiliates, and any other interested parties, will include a short presentation on the state of the Digital Archive of Literacy Narratives (DALN).

\section{B.UGRS Undergraduate Research Symposium}

George's @ the JC I Panel

Thought Processes Behind YouTube and its Composition Methods

Simon Cruz, Monmouth University

Digital Censorship in the Social Media World FeiFei Ma, University of Maryland, Baltimore County 


\section{Keynote \& Lunch Friday, May 25th 12:00 pm - 2:00 pm}

Dr. Elizabeth Losh

\section{Hastag Feminism and Its Discontents} JC - Dewberry | Keynote

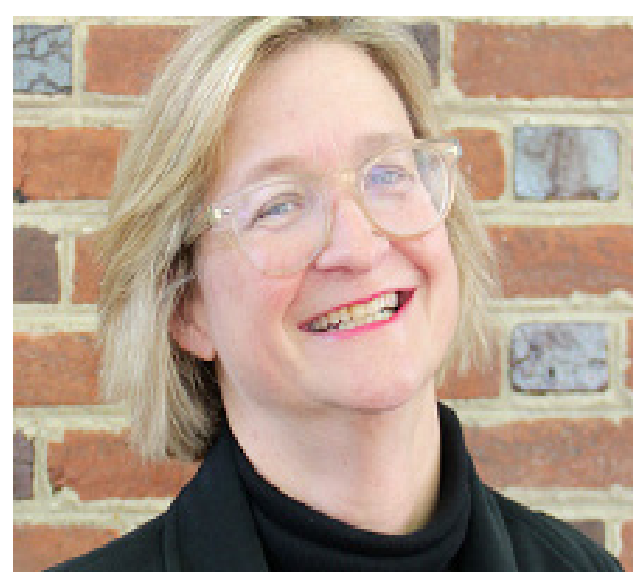

Celebration and criticism of so-called "hashtag feminism" rarely addresses the hashtag itself as an artifact or tries to locate its place in the history of information design. Although the story of the hashtag tends to be associated with Silicon Valley invention myths or power

users like celebrities, the hashtag is actually the result of accreted sets of practices and invisible labor involving negotiating competing claims about identity, ownership, and naming conventions.

Elizabeth Losh is an Associate Professor of English and American Studies at William and Mary with a specialization in New Media Ecologies. Before coming to William and Mary, she directed the Culture, Art, and Technology Program at the University of California, San Diego. She is a core member and former co-facilitator of the feminist technology collective FemTechNet, which offers a Distributed Open Collaborative Course, a blogger for Digital Media and Learning Central, and part of the international organizing team of The Selfie Course. She currently serves on the Executive Council of the Modern Language Association. 


\section{Concurrent Session C Friday, May 25th 2:15 pm - 3:30 pm}

\section{C.1 Electronics Composition: Paper-based Circuit Crafting and Physical-Digital Texts}

Fenwick 1014A | Mini-Workshop John Walter

This mini-workshop introduces paper-based circuit crafting as a form of material composition, detailing how paper-based circuit crafting has been and might be used in composition classrooms; participants will learn to craft three basic paper-based circuits of their own.

\section{C.2 Feminist Methodologies That Engage Emergent Social Justice Issues in the Digital Writing Classroom}

Fenwick 1014B | Mini-Workshop

Julie Bates, Sarah Warren-Riley, Lisa Phillips

Panelists present a case study arising from an of-the-moment social and environmental justice exigency; panelists will share potential pedagogical strategies for bringing the issue into the computer-mediated classroom. Participants will leave with ideas for in-class activities and research projects.

\section{C.3 Writer/Designer: Making Multimodal Projects in Your Classes}

Fenwick 4010 | Mini-Workshop

Cheryl Ball, Jennifer Sheppard, Kristin Arola

This session, part roundtable, part workshop, takes its exigence from the co-presenters' second edition of the textbook, Writer/Designer: A Guide to Making Multimodal Projects. Presenters will work with participants on areas of specific need in relation to the book's client- and process-based approaches. 


\section{C.4 Design Thinking and Game Design: A Productive Relationship for Writing Pedagogy?}

JC-A | Roundtable

Sarah Lozier-Laiola, Joy Robinson, Laquana Cooke, Lisa Dusenberry

In this roundtable, we explore design thinking through gaming as a way to introduce ambiguity by considering the following questions: How do we define and interpret games design and development processes used in academic settings? How do we prepare the classroom space to support the design thinking activities through game development? What are the best ways to introduce the ambiguity required for design thinking through game development in the classroom? How do we infuse productive failure opportunities as an essential part of design thinking in the classroom?

\section{C.5 Representing Diversity in Digital Research: Digital Feminist Ethics and Resisting Dominant Normatives}

JC-Gold Room | Roundtable Ashanka Kumari, Chris Lindgren, Kyle Larson, Les Hutchinson, Sweta Baniya

The speakers in this roundtable consider how their engaged practices of feminist ethics have come up against specific dominant normatives. Privileging the experiences of women of color, they question the embodied relationship they have with their research participants, and offer their methodological approaches for addressing ethical challenges that have surfaced through conducting their research in both digital and non-digital spaces. 


\section{C.6 Reading (and the) Interface}

Fenwick 3001 | Panel

Guerilla Wondering: Language-Modifying Chrome Extensions to Hack the Interface of Web Reading Elizabeth Chamberlain

Quantifying Reader Response: Towards a Mixed Reading of Media Experiences

John Murray

Social Annotation and Layered Readings in Composition Michelle Sprouse

Elizabeth Chamberlain discusses writing a language-modifying extension to chrome; John Murray discusses the interplay of physiological signals and machine learning; and Michelle Sprouse discusses social annotation, primarily in the context of first-year composition.

\section{C.7 Activism in Virtual Publics}

Fenwick 4008 | Panel

Sex in Networked Publics

Sandra Nelson

Design Justice: Creating Change with Communities Aimée Knight

Locating an Ethic of Dissent in the Virtual Town Hall Kristina Fennelly

Sandra Nelson considers the ways Facebook and FetLife operate as contrasting digital publics through site policy and interface options; Aimée Knight explores how we can use a Design Justice Philosophy in our teaching and research; and Kristina Fennelly examines "argument culture" in social media forums like Facebook and Twitter.

32 | Concurrent Session C 


\section{C.8 "Translation Moments" as Phronesis in Classrooms and Communities}

JC-B | Panel

Cristina Sanchez-Martin, Laura Gonzales, Elvira Carrizal-Dukes

Drawing on recent work that highlights the importance of linguistic diversity in technical communication and computers and composition, this panel situates the activities of translation as sites of innovation and rhetorical power.

\section{C.9 Digital Citizenship at the Crossroads: Inter- sections between Phronesis, Classrooms, and the Internet}

JC-C | Panel

Scott Caddy, James Neel, David DeVine, Ibrahim Alaswad This panel addresses the integration of digital humanities and games theory into traditional and "hybrid" literature and composition classrooms.

\section{C.10 Diversifying Digital Civics: Video Games, Participation, and Interface at Three Different Institutions}

\section{JC-D | Panel}

Civic Rhetoric and Digital Participation: Civilizing Social Media One Class at a Time

Alice Henton

Designing Civic Interfaces to Reduce Online Harassment John Gallagher

Across the Digital Divide: Civic and Rhetorical Agency in Digital Game Studies

Rebecca Tarsa

Our panel explores the intersection of civic engagement and student experience with a look at three different assignments taught at three different institutions. Each panelist discusses the challenges of situating civic rhetoric within a specific digital context. 


\section{C.11 Digital Rhetoric: Invention}

JC-E | Panel

Practice Pataphysical: Rhetorical Invention and

Find/Replace Technologies

Paul Muhlhauser

Software Libraries as Computational Topoi

Kevin Brock

Customizable Phronesis: The Making of Writing

Caleb Andrew Milligan

Paul Muhlhauser discusses how pataphysics, or the science of imaginary solutions, can be used for disruption and invention; Kevin Brock considers software libraries-as-topoi; and Caleb Andrew Milligan demonstrates a project to construct a personalized writing apparatus using Raspberry Pie.

\section{C.12 Preaching What We Practice: How We Ap- ply Our Artistic Selves to Our Writing Instruction}

JC-F | Panel

Christopher Ritter, Patrick Johnson, Jim Haendiges

Speaker 1 shows how to use Microsoft OneNote to teach listening, reading, and writing skills; Speaker 2 will discuss how playing music contributes to teaching writing principles; and Speaker 3 will share how his experiences writing screenplays and comic scripts shape his conversations about writing with students, peer tutors, and faculty.

\section{C.13 The Machine Rhetorics of Bots}

\section{JC-G | Panel}

Praise and Blame of Social Media Bots: Rhetorical agency and ethics in the age of algorithms Aaron Geiger

A Question of Phronesis: Does a Chatbot Talk to Itself?

Marcia Bost

Robot Writing Teachers: 3 Artifacts

Jimmy Butts

34 | Concurrent Session C 
Aaron Geiger discusses bots and rhetorical agency between rhetors and technology; Macia Bost considers theories of digital agents' agency in the context of definitions set by sociologists Mustafa Emirbayer and Ann Mische; and Jimmy Butts demonstrates several approaches to algorithmic textual generation in the classroom.

\section{C.14 Digital Phronesis and Technofeminism}

\section{JC-239 | Panel}

Writing and Living in Digital Spaces: A Case Study of Saudi Females' Use of Social Media

Manea Alharbi-(Cancelled)

Feminist Approaches to Digital Phronesis: Fostering Girls' Digital Literacies at Tech Camp

Carrie Gant

TechnoFeminist, Citizen, Activist Writer/Designer?

Dànielle Nicole DeVoss

Manea Alharbi presents findings from a case study of Saudi females' use of social media; Carrie Grant shares findings from a study conducted with a for-profit girls' technology camp; and Dànielle Nicole DeVoss discusses what a technofeminist, citizen, activist writer/designer might look like from rhetorical theory, design studies, and rhetoric and writing perspectives.

\section{C.UGRS Undergraduate Research Symposium}

George's @ the JC | Panel

Digital Videos as Required Writing Assignments in College-Level English Courses

Skyler Schack, Monmouth University

Usefulness of Discussion Boards in College Composition Courses

Charlee Helmstetter, Monmouth University

The Digital Humanities and How It Has Integrated Technology and Literature: A Clarification Anthony Varlese, Monmouth University 


\section{Concurrent Session D \\ Friday, May 25th \\ 3:45 pm - 5:00 pm}

\section{D.1 From Fake News to Predatory Journal Platforms: Reclaiming the Lost Art of Source Evaluation}

Fenwick 1014A | Mini-Workshop

Norah Fahim, Chris Kamrath, Jenae Cohn

This workshop is designed to address the rise of two parallel phenomena affecting our students' research practices: Fake News and Predatory Journals

\section{D.2 Between IRL and Digital Spaces: CUNY's CompComm Faculty Playfully Collaborating}

\section{JC-A | Roundtable}

Andréa Stella, Anna Zeemont, Jesse Rice-Evans, Lindsey Albracht, Seth Graves

This roundtable will discuss how our organization-open to both graduate students, instructors, and writing program administrators-fostered a variety of cross-campus digital culture and digitally facilitated mentorship projects by informal structures of "practical wisdom" and peer mentorship.

\section{D.3 Place/Interface: Situating Space as Ways of Knowing, Accessing, and Remembering}

Fenwick 1014B | Panel

Krystin Gollihue, Ragan Glover-Rijkse, Mai Xiong

The first presenter examines the interactions between local and colonizing depictions of a World Heritage Site in Laos. The second presenter examines the gentrification of textile mills in central North Carolina.The final presentation examines issues of disability and mobility in rural spaces. 


\section{D.4 Institutional Infrastructure for Digital Writing}

Fenwick 3001 | Panel

Infrastructure in the Contemporary University

Courtney Werner

City Tech's OpenLab as Digital Writing

Jill Belli

MOOCs Beyond the Dead: The Rapid Rise, Fall, and (Fuzzy) Future of Massive Online Open Courses

Steve Krause

Courtney Werner discusses changes in education since Devoss, Grabill, and Cushman's 2005 study "Infrastructure and Composing: the When of New-Media Writing"; Jill Belli reviews a taxonomy created for composing activities in OpenLab; and Steve Krause examines the rise and fall of Massive Online Open Courses.

\section{D.5 The Phronesis of Teachers of Color: Intersectional Approaches to Technology in the Writing Classroom}

Fenwick 4010 | Panel

From the top of the Dome: HipHop Pedagogical Sensibilities in the Writing Classroom

Victor Del Hierro

Making Way Outta No Way: Tapping on Students' Classroom Tactics to Enable a Pedagogy of Access in an HBCU Esther Milu

Using Feminist Rhetorical Practices to Make and Keep Space: A Teacher of Color's Reflections on Developing "Counter-Courses"

Ronisha Browdy

In this panel, presenters discuss the complex pedagogical space of being a person of color in a classroom of students that is increasingly diverse. Each presenter will discuss examples of innovations built from the relationship between their embodied experience and their students in their writing classrooms. 


\section{D.6 Experiments in Transductive Writing and Rhetoric with the Kinect}

Fenwick 4008 | Panel

Matthew Halm, Steven Smith, David Rieder

This panel will present a series of experiments using the Kinect sensor to transduce the human body to create digital forms of writing and rhetoric.

\section{D.7 A Polyphony of Voices, Images, and Meth- ods: Designing and Enacting Today's Digital Writing Research \\ JC-B | Panel}

Soundwriting as Research Method: Mediating Undergraduate Discourse Studies Crystal VanKooten

A Methodology of Interdependence through Video as Method

Christina Rowell

Capturing a Dynamic Whole: Multimodal Methods for Mapping Composing Processes Jennifer Buckner

Speaker one will explore soundwriting as research method through analysis of an undergraduate multimodal portfolio. Speaker two will examine the use of video within qualitative research as a tool for data collection, analysis, and presentation. Speaker three will discuss the use of video, audio, and screen capture technologies for collecting data on multimodal composing.

\section{D.8 Engaging Pedagogies for Student Success in Undergraduate Service Courses}

JC-C | Panel

Jill Heney, Debra Purdy, Heidi Naylor

This panel presents two studies on student participation and engagement: implications from an NSF-funded study of introductory technical and professional communication (TPC) courses as well as findings from a study of an online first-year writing course.

$38 \mid$ Concurrent Session D 


\section{D.9 Digital Accessibility}

JC-D | Panel

Course Management Systems as Sponsors of Accessibility Jathan Day

Cripping Metadata

Melanie Yergeau

Digitizing the Writing Process through Assistive and Augmentative Communication Devices

Margaret Moore

Jathan Day repurposes Brandt's 1998 concept of literacy sponsorship to examine how course management systems postion and promote themselves as sponsors of accessibility; Melanie Yergeau argues that the classification schema of metadata may perpetuate stereotypes of disability; and Meg Moore demonstrates the full cycle of the writing process through assistive technologies.

\section{D.10 On-the-Spot Assemblages: Moving Litera- cies Across Digital and Physical Spaces}

JC-E | Panel

Literacy, Mobility, and Collaborative Writing on the 7 Train Ana Cortes Lagos

Traveling Theories: WAC Meets Digital Rhetoric in a Transnational Learning Space

Brice Nordquist

Prison Circuits: To Discern, Learn, and Compose (or Connect)

Patrick Berry

Sharing a framework oriented to interdependencies of material, embodied, digital, and communicative mobilities (Sheller, 2014), this panel offers more nuanced accounts of knowing, learning, and practical wisdom as literate actors and artifacts are revised and re-coordinated across space, time, and media through a series of case studies extending across spheres of activity-from subways to cellblocks, from college classrooms in Chile to the streets of Harlem. 


\section{D.11 Interactive Fiction and Hypertexts: Experiences with "Text Adventure" Authoring Tools in Writing Courses}

\section{JC-F | Panel}

Working Within the Space of Interactive Fiction: Passion, Authorship, and Remix

Daniel Frank

The Natural Accommodation of Interactive Fiction: How Text-Based Games Remove Barriers to Participation Christopher Wyatt

Possibility and Play: Game Writing and Game Studies as Liberating Praxis

Morgan Read-Davidson

Quest with Class: Interactive Fictions and Diversity Lauren Woolbright

Panelists discuss their experiences with using interactive fiction (IF) and hypertext authoring tools within writing courses and across the curriculum, offering suggestions for effective student projects.

\section{D.12 The Phronesis of Social Media Research: Findings on Digital Discourse, Citizenship, and Ethics}

\section{JC-G | Panel}

Findings on Social Media Use in Undergraduate Classrooms

Stephanie Vie

Social Media Composing for Digital Citizenship Jennifer Miller

Studying Discourse Disruption through Hashtags:

\#OrlandoStrong and Digital Rhetoric Bill Wolff

Archives, Bots, Fake Accounts, and the Emerging Ethical Complexities of Social Media Research Nicholas DeArmas 
Contemporary scholarship in writing studies has considered social media from various angles, including how it may be incorporated into the classroom and academia in general. This panel seeks to continue discussions of how social media serve as a viable and robust site for cultivating meaning and identification though practitioner and student research.

\section{D.13 Preservation, Curation, and Researching in the Archives}

\section{JC-239 | Panel}

Preserving Digital Scholarship: Variable Media Questionnaire Case Studies

John Walter

Unseen Anxieties: Uncovering Technology Tensions in a Hidden Archive

Ian Golding

Feminist Archiving as Phronesis: Archive of Our Own and Creating Space for Interactive Digital Curation Lee Hibbard

This panel discusses preservation, curation, and the boundaries of digital archiving and curation processes. John Walter uses the Variable Media Questionnaire, a preservation heuristic developed by the Guggenheim and the Langlois Foundation for ephemeral and multimodal art; Ian Golding reexamines the history of technology within the 1990s composition class through a previously undiscovered cache of twenty year-old writing student portfolios; and Lee Hibbard describes feminist archiving as phronetic process, highlighting the work of the website Archive of Our Own (AO3). 


\section{D.14 Cs The Day Card Game Playtesting}

Fenwick 4001 | Play

Wendi Sierra

Cs the Day: The Card Game pits players against each other to compete for tenure. Teach classes, serve on committees, and desperately try to get the right combination of cards to hit that holy grail of tenure: a monograph! Note: play testing CtD: TCG will not grant you tenure at your home institution.

\section{D.UGRS Undergraduate Research Symposium}

George's @ the JC | Panel

3D Printing and the Importance of STEM and Humanities Collaboration in Utilizing Emerging Technological Capabilities Madison Jewell, Wright State University

Exploring the Ethical Concerns of Brain-Computer Interface (BCI) and Transhumanism: A Choose-Your-OwnAdventure Webgame Haley Shea Barfield, University of North Georgia 


\section{Awards Banquet Friday, May 25th 6:00 pm - 8:00 pm}

JC - Dewberry | Dinner and Awards

Join the Computers and Writing Community as we recognize the outstanding achievements in our field.

Awards and Announcements:

Hawisher and Selfe Caring for the Future Award

Kairos Awards

Computers and Composition Awards

Digital Rhetoric Collaborative Book Prize

7C Awards

Announcement of the 2019 Computers and Writing Conference!

Friday Night - Bowling! 8:30pm - Midnight Bowl America

5615 Guinea Rd, Fairfax, VA 22032 


\section{Concurrent Session E Saturday, May 26th 9:00 am - 10:15 am}

\section{E.1 Text Visualization Tools}

Fenwick 1014A | Mini-Workshop

Madeleine Sorapure

This hands-on mini-workshop will introduce participants to a number of tools (most free) that allow them to analyze and visualize text in different ways. During the workshop, participants will be able to use the tools in order to visualize texts of their choosing.

\section{E.2 Meaning-Making and Randomization in E-Poetry Machines}

Fenwick 1014B | Mini-Workshop

Amanda Hill \& Laura Moeller

This mini-workshop will begin with a discussion of two e-poetry projects, both of which piece together moments of coded pattern and randomness to create new digital poetic works, created by the facilitators. The workshop includes an interactive experiment where the audience members engage in the building of a new poem as if they were coded computer machines.

\section{E.3 Digital Distribution and Programmatic Progression: An Examination of Ideology in a Badging Initiative}

JC-A | Roundtable

Alan Reid, Becky Childs, Denise Paster, J. Daniel Hasty

Coastal Carolina University recently launched a digital badging program designed to support students as they enter the university setting as readers and writers. Four key contributors to this badging initiative highlight the ways this digital delivery system brings a theoretically driven philosophy of language to composition classes across our campus. 


\section{E.4 Teaching with Technology in Global Contexts}

Fenwick 4010| Panel

International Students' Perceptions of Mediated P2P

Review: Subjectivities and Experience

Douglas Walls \& Nupoor Jalindre

Technology in the Teaching and Learning of FYC in

Ghana

Stephen Boakye

Doug Walls and Nupoor Jalindre discuss the effectiveness of peer-review pedagogies in a tech comm course populated by international and native language learners; Stephen Boakye presents findings from a study of a Ghanaian university's Communicative Skills (FYC) program.

\section{E.5 Prosumers: Fan Fiction and Wikipedia} Fenwick 3001 | Panel

Living \& Writing Fandom: Affordances and Consequences of Fan Platforms

Rachel Atherton

The Pedagogical Benefits of Fanfiction: Assigning a

Fanfiction Writing Project

Erika Romero

Why Wikipedia Matters to the Humanities

Melanie Kill

Rachel Atherton uses feminist and queer theories in an autoethnographic analysis of fanfiction; Erika Romero argues that instructors should include fan writing practices in the writing classes; and Melanie Kill suggests that Wikipedia could benefit from contributions of scholars in the humanities. 


\section{E.6 Strategies for Digital Advocacy, Access, and Empowerment}

Fenwick 4008 | Panel

A Sign of Digital Embodiment in Online Videos

Janine Butler

\#AcademicAbleism and the (In)Accessibility of Digital

Writing

\section{Allison Hitt}

Embodied Experiences, Disembodied Compositions

Sushil K. Oswal

This panel examines how disabled users mark their embodied difference in digital spaces, which is not only embodied but also disabled in exciting and fruitful ways. As the panelists will illustrate, this disabling of the digital provides avenues for activism and advocacy that are accessible to divergent mindbodies.

\section{E.7 User-Centered + Design JC-B | Panel}

Improving International Students' Experiences in Online Writing Courses: A User-Centered Approach to Culturally Responsive Interface and Instructional Design Bethany Monea

Not Idiots Anymore: Users as Creative Innovators Isidore Dorpenyo

Writing with Users in Mind: Multimodal Composition as Design Research

Will Kurlinkus

Bethany Monea proposes a research-based strategy for enhancing cross-cultural interface and instructional design; Isidore Dorpenyo examines the redesign of a biometric technology manual for use in Ghanian elections; and Will Kurlinkus draws on the field of design studies to describe a multimodal composition curriculum. 


\section{E.8 Abstract Transmediations: Transferable FYW Outcomes in the Digital Age}

JC-C | Panel

Christopher Stuart, Brian Gaines, Victoria Houser, Jan Rune Holmevik

Clemson University's first-year composition (FYC) program conducted a pilot study means to test the viability of a fully digital writing course, exploring the implications of using creativity software, media theory, and traditional elements of argumentation.

\section{E.9 Exploring Pedagogies for Synchronous Video Writing Instruction JC-D | Panel}

Collin Bjork, Kimberly Fahle, Shelley Rodrigo

Based on a combination of rhetorical theory, pedagogical research, and personal experiences, these presentations examine how pedagogues a) craft their digital teacherly ethos, b) select methods of discursive engagement, and c) assess the impact of synchronous participation.

\section{E.10 Panel, Interrupted}

JC-E | Panel

Sebastian Ivy, Amber Lee, Nathan DeProspo, Byron Hawk (Chair)

How does digital memory interrupt conceptions of human memory? How does the digital world interrupt power structures, sovereign forces, and conceptions of autonomy? How do processes of subjectivity function in digital economies? How do digital sonic compositions enable the creation and revision of collective identities? Working through these questions, the panel looks to theorize alternative ways of ethically composing and inhabiting the digital world. 


\section{E.11 Reading and Writing about Bodies and Technology: Imagining a Rhetorical \\ Technofeminist Pedagogy}

\section{JC-F | Panel}

Rhetorical Technofeminism in the First-Year Writing Class Kaitlin Clinnin

Interdisciplinarity and Technofeminism: Teaching Fat Activism

Katherine DeLuca

Revising and Reenvisioning Classroom Practice from a Rhetorical Technofeminist Perspective

Katie Manthey

Building on work in intersectional, feminist rhetorics and technofeminism, this panel explores rhetorical technofeminism as a generative framework for praxis. Panelists will review their own classroom practices and experiences, connecting the theoretical concepts of rhetorical technofeminism to embodied, everyday praxis.

\section{E.12 The Fallacies of Open: Participatory Design, Connected Learning, and The Pursuit of Radical Possibility}

\section{JC-G | Panel}

Anna Smith, Christina Cantrill, Stephanie West-Puckett

The concept of "open" promises frictionless sharing of knowledge, knowledge pathways, and knowledge-making resources. Our analysis of emergent relationships in the National Writing Project's Making Learning Connected MOOC (CLMOOC) suggests, however, that the "open" in "open learning" is a fallacy.

\section{E.13 Cs The Day Card Game \& TextJam Playtesting}

Fenwick 4001 | Play

Wendi Sierra, Dan Frank

Join Wendi and Dan as they seek playtesters for their C\&W community-developed games. 


\section{E.14 Digital Literacies}

\section{JC-239 | Panel}

Digital Literacy as a Spectrum: Institutional Responsibility for Digital Outcome Implementation

Jennifer Hewerdine

The Podcast Voyager: Launching A Podcast Literacy Probe Matthew Jacobson

The Politics of Literacy Instruction in Computers and Composition: An International Journal 1990-2015

Lynn Reid

Jennifer Hewerdine argues that institutions that implement digital literacy outcomes or digital outcomes of any kind have an ethical imperative to ensure access, infrastructure, and faculty and staff training; Matthew Jacobson introduces and launches a cultural probe-a design studies data gathering method-to help build podcast literacies; and Lynn Reid presents a qualitative analysis of Computers and Composition: An International Journal focused on how scholarship in the journal has contributed to disciplinary expertise regarding the politics of literacy instruction in higher education.

\section{E.UGRS Undergraduate Research Symposium}

George's @ the JC | Panel

"Some Very Fine People On Both Sides": Unpacking Reddit's Reactions to Charlottesville Anthony Saylor, University of Maryland, Baltimore County

Partisan Memes for Political Dreams: A Look at How the Left and Right Harness the Internet's Power Ashley Brooks, University of North Georgia - Gainesville

Political Discourse on Twitter Around the Government Shutdown

Willa Murphy, University of Maryland, Baltimore County 


\section{Concurrent Session F Saturday, May 26th 10:30 am - 11:45 am}

\section{F.1 Memes and r/NoSleep: Digital Reactions to the 2017 Election with Pedagogical}

\section{Implications}

Fenwick 1014A | Mini-Workshop

Rachel Winter \& Emily Hensley

This interactive workshop will focus on the phronesis of Twitter and r/NoSleep users, who have combined their learned knowledge about the production and dissemination of digital media with their lived experience regarding the $2016 / 2017$ elections in the US.

\section{F.2 Developing Digital Humanities Programs within Existing English Departments-(Canceled)}

Fenwick 1014B | Mini-Workshop

Stephanie Hedge

This workshop takes a programmatic approach to incorporating Digital Humanities courses and tracks into existing English programs, offering strategies for developing program goals, pitching $\mathrm{DH}$ to administrators and (sometimes) reluctant faculty, building strong courses and sequencing, and supporting faculty and student digital research.

\section{F.3 Konsult: An Invention-Based Learning Model Sparked by Digital Creativity}

JC-A | Roundtable

Jan Rune Holmevik, Amy Patterson, Chelsea Slack, Eric Hamilton, Shauna Chung, Shelley Lloyd, Victoria Houser This roundtable focuses on Gregory Ulmer's concept of the Konsult, a new site of electrate learning that brings students into attunement with the disaster. Six Konsults will be presented and discussed from both a scholarly and a creative perspective.

50 | Concurrent Session F 


\section{F.4 Online Writing Instruction}

Fenwick 4010 | Panel

Beer Deconstructed: Designing Short Weekly Writing Assignments in a Fully Online Beer and Brewing Course Alex Rockey \& Kem Saichaie

Compose, Design, Educate: Developing a Digital Rhetorics Themed Online Writing Course

Allegra Smith

Friends Don't Lie: Eleven, Why Fetishinzing Community In OWI Is Disingenuous, and What We Can Do About It Kevin Eric DePew

Alex Rockey and Kem Saichaie share their experience in designing short, weekly, writing assignments for a fully online course; Allegra Smith traces the design and implementation of an online first-year composition course at an R1 institution; and Kevin Eric DePew discusses OWI Principle 11, and questions whether discussion board pedagogies foster communal engagement.

\section{F.5 Agency, Resistance, and the Case Against Social Media}

Fenwick 3001 | Panel

"The Truth Is [Not] Out There": Rethinking Student and Instructor Agency in the Age of Government Surveillance David Maynard

Assembling the Phronetic Case Against Social Media Stephen McElroy

Design and Usability Methods to Combat Fake News Nupoor Jalindre

David Maynard suggests that despite technical advances such as end-to-end encryption, networked digital technology constitutes an alien frontier in which instructor and student agency remains tenuous; Stephen McElroy argues that it may be in your best interests, and in the best interests of us all, to delete your Facebook account; and Nupoor Jalindre presents methods for training technical communicators to employ visual design and user experience strategies to combat fake news. 


\section{F.6 Teaching with Social Media}

Fenwick 4008 | Panel

Networking Outcomes: Implementing Social Networking Sites in the FYC Classroom

Joel Bergholtz

Simulating Facebook's Newsfeed for Public Writing Pedagogy

Daniel Libertz

Owning Your Digital Shadow: Students' Right to Their Own Data

Mike Edwards

Joel Bergholtz presents strategies for implementing Social Networking sites into the FYC classroom; Daniel Libertz argues that writing constraints produced by algorithms can become accessible topics for writing instruction by using a simulation; and Mike Edwards argues that in an educational environment increasingly dominated by digital dataveillance for economic gain, instructors must be mindful of their ethical obligations to protect students' right to their own data.

\section{F.7 Adopt-Adapt-Create: Teaching Digital Archival Practice through Collaboration in Technical Communication}

\section{JC-B | Panel}

Erin Brock Carlson, Michelle McMullin, Patricia Sullivan

This panel argues that archival practices should be explicitly discussed and taught in technical communication courses; we further contend that digital archives should be presented as interactive platforms with material implications for their creators and users, rather than as mere containers of artifacts. This dynamic and digitally rich approach to teaching archival practice allows students to make connections between project management, information architecture, data storage, and retrieval, as well as the rhetorical, ethical and inventive choices they make in technical communication.

52 | Concurrent Session F 


\section{F.8 Formal Learning Meets Embodied Experi- ence in the Computer Mediated Classroom}

JC-C | Panel

Oriana Gilson, Lisa Dooley, Sarah Warren-Riley

This panel highlights our experiences as doctoral students teaching technical communication for the first time in computer mediated classrooms predominantly populated by undergraduate IT majors.

\section{F.9 Gameplay, Choice, and Ethos in Writing Classrooms JC-D | Panel}

Flip it, game it, play it, grade it: a harder, better, faster, stronger pedagogy for FYC

Emi Stuemke

Gameplay and Operational Constraints in Digital

Storytelling

Rebekah Shultz Colby

Examining the Ethos Construction of Metis and Phronesis in Gameplay

Cody Reimer

This panel looks at the role of gameplay in foregrounding student choice in flipped and advanced writing courses.

\section{F.10 Valuing the Practical Wisdom of Practi- tioners: How Workplace Writing Research Can Change Writing Instruction}

\section{JC-G | Panel}

The Phronesis of Proposal Writing Heidi Lawrence \& Rachael Lussos

Archive of Workplace Writing Experiences: A Digital Audio Collection and Inquiry into Professional Writing Development

Brian Fitzpatrick \& Jessica McCaughey

This panel reports on two multi-year studies that demonstrate how writing instructors can tap into the practical wisdom of workplace writers through qualitative research. 


\section{F.11 Remediating Recipes: Food and/as Lived Experience}

$J C-F \mid$ Panel

Inedible Rhetoric: On Kitchen Creativity and Food Crimes Jody Shipka

Fixing Memory: Recipes as Code, Artifact, Phronesis Devon Ralston

Maternal Phronesis: Coding Sensed Cultures in Kitchens Brianne Radke

Following Barthes and others who have suggested that entire worlds are created by, present in, transformed and communicated through food, we are interested in exploring food as a kind of code and coding practice.

\section{F.12 Pedagogy as Phronesis: Practical Heuristic Approaches to Teaching Composition}

JC-E | Panel

Developmental Writing, Video Games, and Composition Pedagogy

Sean Whelan

Writing with Video Games in First-Year Writing

Samuel Stinson

Teaching Procedural Rhetoric and Visual Enthymeme in the Science Writing Class

Garrett Cummins

Teaching Creative Storytelling and Critical Argumentation through Heuristic Play

Jon Stansell

Games in the composition classroom are phronetic, interactive multimodal texts that encourage students to further grow as writers through project-based learning, based on learner investment and interest through heuristic approaches. The four approaches included in this panel presentation focus on developing game-like heuristic activities to teaching composition in the developmental, first-year, and science writing classrooms. 


\section{F.13 Pedagogies of Writing for the Web \\ JC-239 | Panel}

Distributed Innovation: Teaching as Co-Learning in Writing for the Web

Elizabeth Davis

Replacing "Writing" with "Content" in the Web-Writing Course

\section{Jason Stuart}

The Promises and Perils of Digital Writing as a General Education Course

Santosh Khadka

This panel discusses distributed innovation in writing-forthe-web pedagogies.

\section{F.14 Negotiating Digital Subjectivity, Privacy, and Data}

JC-Gold Room | Panel

The Problem with "Practical Wisdom" Offered by (Digital) Intellectual Property Gatekeepers

Jim Purdy \& Karen Lunsford

The Interface between the Learned and the Lived: Changing Perspective to Unflatten Meanings

Laurence Jose

Understanding Digital and Material Writing Contexts through Cognitive Niche Theory

Julia Romberger

Panelists discuss intellectual property laws and myths, challenging the fixed viewpoint, and material influences on writing practices.

\section{F.UGRS Undergraduate Research Symposium}

George's @ the JC | Panel

The Road Less Traveled: A Documentary Film Ashly Merced, Stony Brook University

Rethinking Teaching: An Exploration of Technology as a Tool in Education

Amanda R. Harris, Wright State University

Communicative Writing through Multimodality Katelyn Caiati, Monmouth University 


\section{Keynote \& Lunch Saturday, May 26th 12:00 pm - 2:00 pm}

\section{Dr. Samantha Blackmon}

\section{Racing Games: On Games, Race, and Community Building}

JC - Dewberry | Keynote

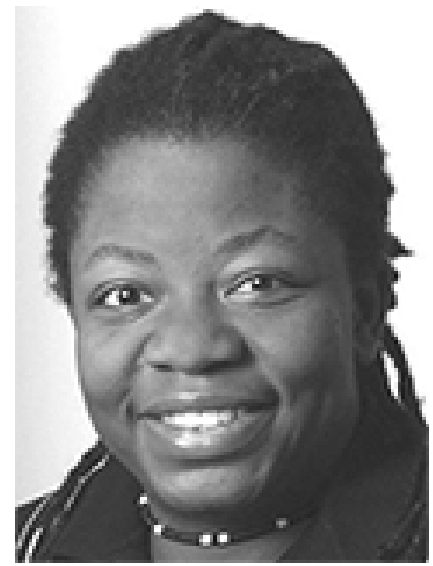

Video games are an interactive medium. We engage with them on a personal and embodied level. This talk focuses on the role that race plays in and around the games community. By viewing video games through a race based or racialized lens we are better able to illuminate the ways that race governs/ influences the experiences of

people who play, teach, and create games. Here I look to and call for less traditional modes of scholarly interaction with games and the games community in an attempt to foster intersectionality and inclusion in our research and knowledge creation practices.

Samantha Blackmon is an Associate Professor of English Rhetoric and Composition at Purdue University. Dr. Blackmon is the Editor of NYMG Feminist Games Studies Journal. Her research and teaching interests are in Minority Rhetoric and Digital Rhetorics. Her more recent research projects looks at identity, video games, and content creators. She is co-editor, with Cristina Kirklighter and Steve Parks, of Listening to Our Elders: Working and Writing for Change (USU Press, 2011), and has published widely in the journals and edited collections of composition, technical communication, and computers and writing. 


\section{Concurrent Session G Saturday, May 26th 2:15 pm - 3:30 pm}

\section{G.1 Composing with Mobile Technologies}

Fenwick 1014A | Mini-Workshop

Gavin Johnson, Laura Allen

In this mini-workshop, participants will consider the intersections of mobile technologies, composing practices, and identity. Our goal is to discuss, generate, and practice pedagogies that actively engage mobile technologies--and participants will also take out their mobile devices and compose with them.

\section{G.2 The DRC as a Digital Rhetoric Playground: Writing in the Classroom, Writing in the World} Fenwick 1014B | Mini-Workshop

Adrienne Raw, Anne Gere, Brandee Easter, Carleigh Davis, Jason Tham, Kristin Ravel, Lauren Brentnell, Lauren Garskie, Naomi Silver

This mini-workshop will work towards finding new ways to play with the materials available on the Digital Rhetoric Collaborative (DRC). Attendees and facilitators will work in small groups to tinker with new ways in which DRC materials might help students bridge writing in the classroom and "out in the world."

\section{G.3 Less Instructions, More Choice: Creating Assignments For All Students}

Fenwick 4010 | Mini-Workshop

Claire Lutkewitte

Through hands-on activities, this mini-workshop will explore practical approaches to writing brief instructions and to helping students use such instructions to create meaningful writing projects. 


\section{G.4 Multimodal Assessment Genres: Helping Students to Research their Writing Practice}

JC-A | Roundtable

Courtney Cox, Charles Woods, Joyce R. Walker, David Giovagnoli, Shane Combs

Panelists consider how "uptake activities" (types of textual productions that focus on documenting and articulating different kinds of learning) can be an essential aspect of visualizing and embedding our knowledge-making practices.

\section{G.5 Multimodal Writing Platforms}

Fenwick 3001 | Panel

The Word is Dead, Long Live the Word - Multimodal

Communication in VR

Gareth Young

Breaching the Screen: A Digital Technofeminist Methodology for Virtual and Augmented Realities

Frank Macarthy

The Digital Sensorium: Considering the Senses in Design Nathaniel Voeller

Panelists address multimodal writing through virtual reality texts-as-objects, augmented reality as a platform for technofeminist methodologies, and sensory composing through synesthesia and phantasia.

\section{G.6 Rhetorical Play(ing): Contemplative Pedagogy, Experience Design, and the Cultivation of Virtue in Multimedia Composition}

JC-F | Panel

Justin Hodgson, Eryn Johnson, Laura Rosche

The concept of play is a both metaphor and mode for thinking through key considerations in multimedia composition, particularly in relation to the classroom as an architectonic space of invention, and each panelist will adopt a different orientation to understanding how play can manifest in a variety of critical considerations for composition.

58 | Concurrent Session G 


\section{G.7 Public Writing Projects}

Fenwick 4008 | Panel

Ecologies of Crowdsourcing a Digital Archive:

Undergraduate Writing and Public Engagement

Katie Bramlett

An Online Undergraduate Research Journal to Demystify

Academic Writing

Thomas Geary

Fieldnotes versus Travel Blog: Teaching live autoethnography to study abroad students

Elizabeth Ferguson

Panelists address modes of writing needed to successfully crowdsource diverse communities for a public event; the development process of an online journal for undergraduate academic writing; and students who use the method of live autoethnography during a study abroad experience to write fieldnotes.

\section{G.8 Algorithmic Authorship}

JC-B | Panel

Cultivating Metic Intelligence Among the Algorithmic Blackboxes of SEOs

Annette Vee

The Work of Art in the Age of Algorithmic Production

Steve Holmes

Computational Audiences and Media Manipulation Timothy Laquintano

Human writers contend with computational and algorithmic writers in their vying for audience and content online. This panel addresses pressing questions about 21st century authorship online, with implications for how we prepare students to write in this brave new world. 


\section{G.9 How to Metamodern Your Classroom}

JC-C | Panel

How to Avoid "Real" Text: Gist Reading and Writing

Paul Muhlhauser \& Daniel Schafer

How to Awkward: Liminal Play in Conflicted Classroom

Robert Kachur

How to Donald Glover: The Transmedia Pedagogy of

Because the Internet

Camden Ostrander

Metamodernity functions at the intersection between

formal structures of learning and the deconstruction of the educational enterprise, where sincerity and irony are experienced simultaneously and not understood to be in conflict.

\section{G.10 Inquiring Minds in Emerging Moments JC-D | Panel}

Inconceivable Encounters and Random Juxtapositions: On Composing Not Knowing

Daniel Anderson

Mixing, Machines, and Materials: On Performing

Composing

Jody Shipka

We consider what might be gained from deploying inquiry to work not toward predefined outcomes and closure but toward opening possibilities for play.

\section{G.11 Virtual Environing: Writing Ecologies with Mobile Media}

JC-G | Panel

Jason Crider, Stephen Quigley, Shannon Butts, Jacob Greene

With more than half of all internet traffic flowing through mobile devices, digital texts are increasingly composed on the move. This panel explores the rhetorical affordances of mobile technologies through a discussion of four location-based digital writing projects.

60 | Concurrent Session G 


\section{G.12 Peer Response Rebooted: Perceptions and Challenges in Digital Environments}

\section{JC-E | Panel}

It's Not a Competition: Using Technologically-Mediated Peer Feedback to Develop Community in Writing Classes Kory Ching

From Google to Eli: Digital Peer Response Tools Mediate Writing Pedagogy

Stacy Wittstock

Perceptions Across Platforms: Students' Experiences with Peer Response in Digital Environments

Tialitha Macklin

Drawing both on classroom experience and a qualitative study of digital peer response, speakers on this panel explore some of the ways technology mediates peer feedback in writing courses.

\section{G.13 Raced Spaces}

\section{JC-239 | Panel}

Black Spaces: How Black Twitter Serves the Black Community as a Public Sphere

Liana Clarke

Raced Spaces: Embodied Marginality in Digital

Contexts

Veronica Garrison-Joyner

Tweeting with Caution: The Risks and Possibilities of Black Women's Digital Literacy On Social Media LaToya Sawyer

Liana Clarke introduces Black Twitter as a public sphere where users can implement change through creating discourse surrounding cultural and political issues and doxing (the act of calling someone out); Veronica Garrison-Joyner explores the cultural-historical situations that contribute to the formation of spaces, symbols, and communities marked by marginality within digital contexts; and LaToya Sawyer highlights prominent examples of backlash against Black women scholars for their critical tweets. 


\section{G.14 LOL - Humor and Composition}

\section{JC-Gold Room | Panel}

The Dictionary Says What?: Irreverent Composition in the Classroom

Tracey Hayes

"Yo Momma is so Rhetorically Sensitive...": Engaging and Developing Students' Sense of "Good Humor" Edrees Nawabi

Tracey Hayes examines the "irreverent composition" present within the Merriam Webster dictionary's tweets as a rhetorical method to define (and clarify language) as a response to the current Trump administration's misuse of words, suggesting that a study of how the dictionary uses a digital space to provide knowledge can determine how "irreverent composition" can be used within the classroom to teach students to participate in our democracy; Edrees Nawabi showcases two major course projects that use "good humor" to develop meta-linguistic awareness and rhetorical sensitivity. 


\section{Concurrent Session H Saturday, May 26th 3:45 pm - 5:00 pm}

\section{H.1 The Politics of the Interface: Still at Play}

(or, how I learned to love it when we bomb)

Fenwick 1014B | Mini-Workshop Molly Daniel, Morgan Gresham, Roxanne Aftanas In this mini-workshop, presenters will describe ways that faculty members can incorporate undergraduate research using digital tools that connect students to real world problems they encounter in their non-school lives.

\section{H.2 The GIF that Keeps on Giving: Assignment Design with Looped Animations}

Fenwick 4010 | Mini-Workshop

Jamie Henthorn, Matthew Beale, Megan Mize

In this mini-workshop, we will introduce participants to pre-existing examples of GIF assignments we have used in courses, discuss avenues for pedagogical research, guide participants in the creation of new GIFs, and facilitate participants' efforts to design assignments that use GIFs.

\section{H.3 Phronetic G-TAHs in a Frenetic World: Preparing Graduate Students for Future Teaching Responsibilities}

JC-A | Roundtable

Alanna Frost, Haley Davis, Kylie Korsnack, Lee Hibbard, Charles Grimm

This panel brings together a seasoned WPA and a cohort of former graduate students whom she trained as composition teachers during their 2-year MA program; discussion will be grounded in reflection and analysis of texts from our time at UAH that have influenced our current teaching practices. 


\section{H.4 Designing Ethical Pedagogies of Play}

Fenwick 1014A | Panel

Verbs of Play: Game Design Patterns and the Challenge of Feminist Gaming Instruction

Anastasia Salter

Video Games as Trolley Problem

Marc Santos

IRC IRL: Twitch Plays Pokemon and the Writing Class Matthew Duncan

Anastasia Salter argues for more inclusive verbs of play; Marc Santos tracks how games force players to make a decision from terrible, seemingly impossible, choices; and Matthew Duncan explores the chat bot model of Twitch Plays Pokémon Red as a tool for writing pedagogy.

\section{H.5 Multimodal Compositions}

Fenwick 3001 | Panel

Multimodal Writing-to-Learn Across Disciplines

Paul Martin

But I thought this was a Composition Class!: Transforming Students' Composing Acts

Jeaneen Canfield

Destabilizing Standardized English and 'Speaking Back' through Multimodal Composition

Maryana Boatenreiter

Paul Martin shows how multimodal writing-to-learn allows students to play with a discipline's semiotic materials; Jeaneen Canfield analyzes students' resistance to a multimodal assignment; and Maryana Boatenreiter extends Christina Cedillo's "Multimodal Homeplaces" to align critical pedagogy with multimodal scholarship. 


\section{H.6 Digital Literacies and Digital Identities}

Fenwick 4008 | Panel

SWIFT Participation: Hacking the Codes of Academic

Writing

Peter Brooks

The Game of Expertise: Using Interactive Digital Learning Environments to Embody Professional and Novice

Perspectives

Matthew Kelly

The Rebel Alliance: Analyzing Student Resistance in

Digital Reflective Writing

Beth Caravella \& Sarah Johnson

Peter Brooks introduces the SWIFT simulation, a semester-long role-playing game; Matthew Kelly has students create their own interactive learning environments using Minecraft; Beth Caravella and Sarah Johnson examine how students' use of "loopholes" illustrate their modifications of and resistance to expectations.

\section{H.7 Bartholomae and Bogost in a Blender: Play- ing with New Definitions of Online Learning Environments}

JC-B | Panel

Allison Hutchison, Andrew Kulak, Lauren Salisbury

This panel discusses online writing course (OWC) designers' responsibilities to space, place, and context.

\section{H.8 Book Unbound: Collaborative Research on Digital Publication in the Humanities}

\section{JC-C | Panel}

Naomi Silver, Adrienne Raw, Anne Gere, Melanie Yergeau

The Book Unbound project considers how to bring digital publication of humanities scholarship to a public, multi-layered audience, through the practical expertise of disciplinary experts from multiple fields working collaboratively on three in-progress humanities publications. 


\section{H.9 Access and Inclusion}

JC-D | Panel

The Application of Rhetorical Listening in Digital Texts for Effective Interaction

Wenqi Cui

Metaphors We Click By: Unpacking Information Overload as Obesity Epidemic

Daniel Liddle

Reconstructing Access and Inclusion in Social Media Barbi Smyser-Fauble

Wenqi Cui suggests applies concepts of circulation and rhetorical listening to multimodal assignments; Daniel Liddle explores comparisons between information literacy and nutritional literacy; and Barbi Smyser-Fauble argues that technical communicators should analyze how social media campaigns impact issues of socio-cultural access and inclusion.

\section{H.10 Weaving Phronetic Threads: Feminist and Cultural Rhetorics Approaches to Professional Writing Curricula}

JC-G | Panel

We Do Things Differently Here: Troubling Notions of "Professionalism" in Professional Writing

Katie Manthey

Localizing Professional Writing Curricula for Diverse Geographies and Economies

Lehua Ledbetter

Telling a Professional Writing Story: Building Relationships to Make Space for a New Curriculum

Maria Novotny

This panel offers multiple curricular approaches from three junior scholars trained in cultural rhetorics who have found themselves creating and implementing professional writing programs at starkly different institutions across the country. 


\section{H.11 Phronesis in Digital Spaces: Agency Shared among Humans \& Technologies}

\section{JC-E | Panel}

Daniel Hocutt, Megan McKittrick, Suzanne Sink

This panel presents three approaches to describing and enacting agency in digital environments: agency in online search as integrated across human activities and algorithmic procedures, agency in digital archives shared across archivist curation and website technologies, and agency in climate change games as enacted in play.

\section{H.12 Composing Digital Public Writing Courses} JC-F | Panel

Specialized Media Tracks: A New Method for Teaching Public Digital Rhetoric

Drew Holladay

Risk Assessment: Public Writing, Student Autonomy and First-Year Composition

Sydney Bufkin

Drew Holladay discusses a multimedia writing course called Social Action and Digital Design; Sydney Bufkin describes the risks and rewwards of a Writing in Public course.

\section{H.13 Digital Texts and eBooks \\ JC-239 | Panel}

Virtual Dust on a Bookshelf: Abandoned Wikibooks by and for Writing Students

Christopher Wyatt

"What is the Use of a Book without Pictures or Conversation?" High-Resolution E-Books in Literary Research Keith Dorwick

Christopher Wyatt investigates how the Wikibook "Professional and Technical Writing" offers an example of a student writing project intended to be self-sustaining that now collects virtual dust on the Wikibooks shelves; Keith Dorwick showcases fully digitized editions of illustrated children's classics. 


\section{H.14 Phronetic Understanding Through Affect: A Rhetorical Analysis of Affective Game Mechanics}

JC-Gold Room | Panel

Opposing Squad Goals: Metanoic Reflection on

Permadeath in the XCOM Series

Christopher Stuart

The MIDA Quest: Destiny 2, Game Objects, and Affective Community Joshua Wood

Locativity, Effective Satire, and Player Affect within Filmic San Andreas

Alex Nielsen

Now We're Playing with Power: When Playful Affect meets Social Justice

Scott Reed

This panel aims to explore the rhetorical implications of affective gaming through an analysis of game mechanics within strategic squad-based games, shooters, role-playing games, and augmented reality. All of these games, though different in play, affect the player and community in similar ways. Presenters will explain affect through the use of mechanics such as fog of war and permadeath; loot and restraining group wisdom, satirical absurdity and interpolation; and jamming serious situations/games. 


\section{Poster Session \\ Saturday, May 26th \\ 5:15 pm - 6:30 pm}

George's@the JC

Agency and Autonomous Monsters in the Age of Fake News

Mark Crane

Celebrities, Fans, and Queering Gender Norms: A Critical Examination of Lady Gaga's, Nicki Minaj's, and Fans' Use of Instagram Brandy Dieterle

Keywords and Concepts in Technical and Professional Communication Joy Robinson

Mobile Composition \& Student Learning: Lessons from Writing in Place Ashley Holmes

Phronesis and Pedagogy: Forms of Ethos in MMORPGs

Wendi Sierra \& Douglas Eyman

Practically Human: What Makes Great Twitterbots

Moe Folk 


\section{Poster Session \\ Saturday, May 26th 5:15 pm - 6:30 pm}

George's @ the JC

Retracing Blogging Experience as Digital Phronesis: Two Multi-cultural Microhistories

Sweta Baniya

What Pinball Teaches Us About Procedural

Rhetoric

Ron Brooks

Changing the Rules of the Game: Reevaluating

Terms of Service for Online Gaming

Lexie Scott (UGRS)

The Magic of Statistics: Revealing the Sorcerer's Secret

Evan Cypher (UGRS)

Procedural Ethos in Videogames

Rebecca Triplett (UGRS) 


\section{Concurrent Session I Sunday, May 27th 9:00 am - 10:15 am}

\section{I.1 Using Clips of Video Games to Teach}

Rhetorical Concepts ... Even if You're Not a Gamer

Fenwick 1014B | Mini-Workshop

Greyson Sanders, Jen Ware, Ashley Hall, Bradley Weng

Inspired by the 8-Bit Philosophy Series on YouTube, the goal of this workshop is to create a series of short videos that illustrate rhetorical concepts through video game play.

\section{I.2 Unspooling Twine: Practical Game Design as Writing and Research Pedagogy}

Fenwick 4010 | Mini-Workshop

Justin Schumaker \& C. McAllister Williams

We will show how game design compliments existing writing pedagogy, introduce the digital game design tool Twine, have participants make their own Twine games, and brainstorm analog game design alternatives.

\section{I.3 Working With Sound: Audiobook Projects, Podcasts, and Pedagogy}

JC-G | Mini-Workshop

Amelia Chesley, Megan McIntyre, Patricia Poblete,

Lauren Malone

The speakers and moderator discuss their questions, experience, and insights about audio recording for audiobooks, for podcasts, and in classrooms. In addition to participating in lively discussion, the audience will walk away from this session with suggested readings for further study, a list of online and accessible tools and resources, possible projects to bring to the classroom, and some first-hand experience in recording. 


\section{I.4 Post-Truth, Post-Trump: Reflecting on the Future of Web Literacies}

JC-B | Roundtable

Jason Luther, Rachael Shapiro, Brett Keegan, Vyshali

Manivannan, Kristin Ravel, Dustin Edwards, Bridget Gelms

This roundtable extends the field's reassessment of web literacies and public rhetoric in the wake of the 2016 election, exploring the personal and pedagogical methods by which we cultivate practical wisdom online in a "posttruth" age.

\section{I.5 Bringing the Game Design Industry to the Writing Class}

Fenwick 1014A | Panel

Doing Interactive Media and Game Development in International, Intercultural Contexts

Jennifer deWinter

Unity in the Classroom: Identity, Community, and Professionalization in Online Courses

D'An Knowles Ball \& Jennifer Hartshorn

Jennifer deWinter shares her research on the global circulation of games, working with students in Sweden and Japan; D'An Knowles Ball and Jennifer Hartshorn explore the ways forums used by independent game developers can be examined as active models for knowledge sharing and professionalization in the classroom.

\section{I.6 Locating Digital Writing Space} JC-D | Panel

Brenta Blevins, Lee Skallerup Bessette, Zach Whalen

This panel seeks to question and to complicate our understanding of what we mean with the term "digital space" by exploring three different sites within their university where 1) physical space demonstrates digital concepts, 2) the digital is overlaid onto physical space, and 3) students compose in a digital space of their own. 


\section{I.7 Circulation, Agency, Virality}

Fenwick 3001 | Panel

Share This Presentation or Get 10 Days of Bad Luck: Developing Students' Critical Literacies for Digital Circulation John J. Silvestro

The Rhetoric of Poppy: Deconstructing the Engagement of a Viral Pop Textual Series

Cynthia Davidson

What Can YouTube Teach us About Rhetorical Agency?

Matt Homer

John J. Silvestro introduces a project that engages students in self-examination of what they did and did not circulate to foster critical literacies of their participatory circulation practices; Cynthia Davidson considers the Poppy project as a series of multimodal texts that prompts writers to reflect on the nature of YouTube celebrity and its audience; and Matt Homer analyzes the demonetization of "non-advertiser friendly" YouTube videos.

\section{I.8 Digital Rhetoric Research Methods}

Fenwick 4008 | Panel

Accounting for How Things Work: An Approach to Using Procedural Rhetoric as Method

Lourdes Fernandez

Collecting Data on Distributed Work: A Video Game Developer Case Study

Matthew Green

Topic Modeling and/as Genre Study

Moriah Kirdy

Lourdes Fernandez describes the design and implementation of a coding schema informed by procedural rhetoric; Matthew Green reports on a pilot study designed to use the participants to collect data on workplace tools and environments that would be otherwise inaccessible; and Moriah Kirdy considers the Latent Dirichlet Allocation (LDA) topic modeling algorithm and its topic-first orientation to study blog posts about the bullet journal. 


\section{I.9 Interface and Embodiment: Connecting Composition through Multimodal Technologies}

JC-C | Panel

It's an Apple: Digital Art Archives in the Age of Alternative Facts

Amanda Stevens

Gaming Intimacies: Relationships with the Embodied Player

Krystin Gollihue

Video Voice: Research as an Embodied Interface Lacee Nisbett

This panel examines interface and embodiment through the personal, the communal, and the scholarly, describing digital art archives, the physical and mental intimacies formed through immersive video game play, and an analysis of the embodied learning experiences of makers.

\section{I.10 Serious Games as Sites of Practicing Research}

\section{JC-F | Panel}

The Amnesia Trope as Procedural Rhetoric: Scientific Research and Uncertainty in Frictional Games' Soma Kenneth Smith

Positionality Challenges the Use of Research in Interactive Fiction Games

Lisa Dusenberry

Contextualizing Research Through Serious Game Design Robert Terry

This panel investigates the intersection between research and playing/designing serious games. Presenters will discuss the procedural rhetoric and experience of research created by playing Soma, the influence the positionality of the programmer has on the presentation of research through games, and the ways writing interactive fiction contextualizes secondary research, creating an inquiry process of productive failure. 


\section{I.11 Building Frameworks for-Coding, Writing, andPublishing a-Bigital-Book-(Cancelled)}

JC-239 | Panel

Kathie Gossett, Liza Potts

Building a digital book is a process in which the author must do the scholarly work of an extended article or monograph plus the application work of building a website, app, or other kind of interactive system to display the scholarship. Working in a Digital Humanities lab with strong backgrounds in user experience and digital scholarship, the team leaders will share their reasoning behind technology choices, their methods for managing processes, and their efforts in implementing the project. 


\section{Concurrent Session J Sunday, May 27th 10:30 am - 11:45 am}

\section{J.1 Thinking with Machines: The Impact of Visualizing Sound on Composing}

Fenwick 1014B | Mini-Workshop

Ben Lauren \& Bill Hart-Davidson

In this interactive and participatory mini-workshop, we extend the results of an experimental project where we worked to understand how DAWs (Digital Audio Workstations) create visual metaphors that shape our perceptions and performances as writers of sound. Additionally, we will explore how sound visualization(s) support a kind of rhetorical cognition in which soundwriters must think with machines via interfaces that respond to how we biologically process sound.

\section{J.2 Writing with File Versions}

Fenwick 4010 | Mini-Workshop

Tim Lockridge \& Derek Van Ittersum

Versioning offers one possible remedy to struggles with file management that we see many writers (students and colleagues) experience. We believe that once writers can abandon the stress of managing multiple files for versions (which prompts confusion about which file is the most up-to-date), they can engage in more free and innovative composing. 


\section{J.3 Multimedia Composition, Soundscapes, and Games}

Fenwick 1014A | Panel

Turning Swords into Spigots: Embodied Multimodal

Composition in Video Game Housing

Danielle Stambler

Playing with Soundscapes: Students' Use of Sonic

Presence in Video Game Narratives

Kati Fargo Ahern

From Poetry to Sonic Perfection: A Case for Teaching Sound Production through Literary Adaptation

Stan Harrison

Danielle Stambler explores how Everquest 2 players go beyond simply placing a couch next to a fireplace as they use thousands of items per "house" to rhetorically invent and arrange rich multimodal texts; Kati Fargo Ahern repors on students' use of sound, auditory imagination, and sonic presence in 10 kinesthetic-based "emplaced" video game narratives; and Stan Harrison shows how teachers can scaffold their students' knowledge of audio production and sound art by having them select and adapt their favorite short poem for sound.

\section{J.4 Workplaces and Digital Literacy}

Fenwick 3001 | Panel

LinkedIn as a Phronetic Approach to Digital Literacy

Theresa Evans

Changing the Context: When the Classroom Becomes a Workplace

Randy Gonzales

Practical Workplace Preparation: Webfolio Assignments in the Intermediate Writing Classroom

Tina Arduini

Theresa Evans elaborates on a phronetic approach to composition instruction using LinkedIn; Randy Gonzales examines an upper-level professional writing course that uses a simulated B2B writing services company; and Tina Arduini addresses the use of webfolios as a practical digital writing assignment in the intermediate writing class. 


\section{J.5 Student Support Structures in Digital Learning Environments}

Fenwick 4008 | Panel

Envisioning a Digital Learning Environment: A Space for Pedagogical Discovery and "Play"

Alex Rockey \& Andy Jones

Constructing Identity/Creating Consubstantiality: How Community College Basic Writing Syllabi Communicate "We"

Erika Johnson

Writing Centers as Tech Support: Redesigning Tutor Training with the "Digital Divide" in Mind

Laura Edwards

Alex Rockey and Andy Jones explain how the digital learning environment (DLE) encourages innovative writing instruction; Erika Johnson uses Linguistic Inquiry Word Count(LIWC2015) to isolate the pronouns I, you, and we to analyze thousands of Basic Writing syllabi; and Laura Edwards shares the design of writing center tutor training which supports students in functional and rhetorical computer literacy.

\section{J.6 Navigating Digital Communities}

JC-B | Panel

Women, Community, and Healing: Cyberfeminist Activities on Reddit

Meg McGuire

What Reddit Can Teach Us about Discourse Communities Ryan P. Shepherd

For High-knowledge Threats: A Placebo-Controlled Rhetorical Trial to Treat Aca-trolls

Vyshali Manivannan

Meg McGuire explores reddit as a space for cyberfeminist activities by analyzing a subreddit for Polycystic Ovarian Syndrome (PCOS); Ryan Shepherd demonstrates how students in FYC explore the communities represented in subreddits; and Vyshali Manivannan asks the audience to experiment with rhetorical strategies that anticipate and mimic troll tactics, as a means to combat them.

78 | Concurrent Session J 


\section{J.7 Mediated Identities in Networked Publics: Audiences, Affordances, and Activisms}

JC-C | Panel

Filters and Finstas: Performing Authenticity and Managing Audience in Networked Publics

Amber Buck

Ill Affordances: Feminism, Facebook, and the Stakes of

Digital Activism

Martha Webber

Open in Public, Hidden from Friends: Pregnancy Loss and Infertility Disclosure on Social Media

Melissa Forbes

"I'm Gay, Y'all!": Coming Out On Facebook in Rural

Alabama

Jesse Cosper

In an environment where users are encouraged to make public disclosures about their personal lives and points of view, the "context collapse" of reducing multiple audiences to a single list of followers raises the stakes on those decisions. This panel brings together research on social media users' rhetorical practices in managing audience on different platforms to represent themselves.

\section{J.8 Writing the Digital World in Multilingual Courses} JC-G | Panel

Attuning Multilingual Students to a Multimodal Context Jennifer Warfel Juszkiewicz

Cinematic Composition and Multilingual Learners Rachel McCabe

Advanced Expository Writing Goes Digital and Multilingual Rebecca Ottman

Nearly one third of all international college students are from China; they are often underprepared for the wider US news media landscape and their role as digital agents within that landscape. This panel will offer three tested pedagogical strategies through which these students can be more attuned to and critical of such a landscape. 


\section{J.9 Negotiating Praxis, Phronesis, and Power through Usability Research and Consulting}

JC-F | Panel

A Rhetorical Turn for Usability and User-Centered Design Bill Williamson

From Consultant to Advocate through Usability

Service-Learning

Steve Benninghoff

Cultivating Phronesis through Usability Research Centers Scott Kowalewski

Our presentations will examine ways usability work can embody phronesis in actively engaging users, clients, and stakeholders in community-building. Faculty running a usability research center, or directing service projects in a graduate course, can assert roles performing civic engagement and as public intellectuals and community advocates.

\section{J.8 Mediating Space through a Digital Lens: Using Digital Composing Tools within a Social Justice Pedagogy Framework}

JC-D | Panel

Digital Dispositions: Cultivating a Social Justice-based Pedagogy to Pursue Equity in Technology Accessibility Erin Dittmer

I'm on the Hunt/I'm After You: Using Geocache to Highlight Rhetorical Awareness

Bri Lafond

$\mathrm{Re} /$ Designing the Multimodal Composition Classroom:

Pedagogy, Curriculum, and Access

Savannah Block

Youth-led Participatory Action Research (YPAR) in the Secondary Setting

Logan Middleton

This panel presentation explores intersections between space, multimodal composition, and social justice pedagogy. 


\section{Lunch and 7C Meeting Sunday, May 27th \\ 12:00 pm - 1:00 pm}

\section{JC - Dewberry Hall}

As we wrap up the conference and look forward to next year's event, please join us for a final meal and conversation. The traditional end-of-conference $7 \mathrm{C}$ meeting will also take place starting at 12:15 in the Gold Room; anyone interested in hosting C\&W or in working to support the C\&W community is welcome to attend!

\section{The After-Party}

Anyone who finds themselves free after the conference is welcome to attend the "after-party" at Chez Doug:

4243 Berritt St. Fairfax VA. (About a 10 minute walk from the dorms). The party will start at $2 \mathrm{pm}$ ! 


\section{Conference Reviewers}

Megan Adams

Jen Almjel

Timothy Amidon

Shawn Apostel

Tina Arduini

Kristin Arola

Anthony Atkins

Deb Balzhiser

Will Banks

Estee Beck

Lee Skallerup Bessette

Christie Bogle

Catherine Braun

Kevin Brock

Elkie Burnside

Janine Butler

Jimmy Butts

David Coad

Tammy Conard-Salvo

Mark Crane

Matthew Davis

Victor Del Hierro

Elizabeth Ferguson

Lourdes Fernandez

Alanna Frost

Laura Gonzales

Matthew Green

Mariana Grohowski

Ashley Hall

Steve Holmes

Chad E. Iwertz

Jim Kalmbach

Erin Karper

Aimée Knight

Lehua Ledbetter

Tim Lockridge
Rachael Lussos

Kristi McDuffie

Ryan Moeller

Jill Morris

April O’Brien

Dawn Opel

Kristopher Purzycki

Lynn Reid

Colleen Reilly

Rich Rice

Shelley Rodrigo

Rich Shivener

Ann Shivers-McNair

Naomi Silver

John J. Silvestro

Madeleine Sorapure

Kyle D. Stedman

Derek Van Ittersum

Matthew Vetter

Douglas Walls

Jen Ware

Bill Wolff

Melanie Yergeau 


\section{Special Thanks To...}

Much gratitude is owed to the folks who work hard to make C\&W a success, both this year and across many years. Shout outs go to:

C\&W 2018 Associate Chair \& Graphic Designer Rachael Lussos

C\&W 2018 Artwork and Logos Beth Caravella

C\&W 2018 Co-Conspirator and Sommelier Steve Holmes

C\&W 2018 Volunteer Coordinator Matt Green

C\&W 2018 Library Liaison Jen Stevens

C\&W Website Administrators Jen Ware Ashley Hall Daniel Anderson

C\&W Mentoring Maven Traci Gardner

Caring for the Future Award Committee Kristin Arola and Cheryl Ball

Graduate Research Network Chairs Janice Walker and Angela Haas 


\section{Conference Volunteers}

Mary Baldwin Sweta Baniya Jackie Brown Beth Caravella Michelle Conklin David Corwin Caitlin Dungan Elizabeth Ferguson Lourdes Fernandez Madeline Graham Steve Holmes Xaviar Jenerette Michelle LaFrance Rachael Lussos Matt Magelssen-Green Laurie Miller Alex Monea Bethany Monea Ashlee Payne Tom Polk Shantay Robinson Robyn Russo Norma Smith Sheri Sorvillo Cheri Spiegel Sommer Marie Sterud Jen Stevens

Ruth Tallman Rebecca Triplett John Walter Ashley Yuckenberg 


\title{
Conference Sponsors
}

\author{
Adobe \\ Eli Review \\ Hybrid Pedagogy \\ W.W. Norton
}

\section{GMU PhD in Writing and Rhetoric GMU MA in Professional Writing and Rhetoric GMU Department of English}

\section{GMU University Libraries}

The University Libraries forms an intellectual nexus for George Mason University. We foster innovation, creativity, and imagination by facilitating access to scholarship and information, providing expert consultation in the research process, and actively teaching the effective and critical use of information. And, we fulfill a critical role in the creation, dissemination, and preservation of knowledge.

The Libraries support the university's mission in a number of ways, including working with students, faculty, and staff throughout the teaching, learning, and research processes; encouraging critical thinking and informed citizenship by supporting digital, data, media, and cultural literacy; and collaborating with on- and off-campus partners to promote and sponsor such events as the 2018 Computers and Writing Conference. For more information, visit library.gmu.edu. 


\section{Participant Index}

Aaron Geiger

Aaron Lanser

Abbie Levesque

Adrienne Raw

Aimée Knight

Alanna Frost

Alan Reid

Alexa Olah

Alex Nielsen

Alex Rockey

Alice Henton

Allegra Smith

Allison Hitt

Allison Hutchison

Amanda Hill

Amanda R. Harris

Amanda Stevens

Amber Buck

Amber Lee

Amelia Chesley

ami Atassi

Amy Patterson

Ana Cortes Lagos

Anastasia Salter

Andréa Stella

Andrew Famiglietti

Andrew Kulak

Andy Jones

Angela Haas

Anna Smith

Anna Zeemont

Anne Gere

Annette Vee

Ann Shivers-McNair

Anthony Saylor

Anthony Varlese
34 April Conway

15

26 Ashanka Kumari

19 Ashley Brooks

57,65 Ashley Hall

13,32 Ashley Holmes

63 Ashly Merced

44 Barbi Smyser-Fauble 66

23 Becky Childs

68 Ben Lauren

44

76

51,78 Ben McCorkle

33 Beth Caravella

17,28

65

18,51 Bill Hart-Davidson $\quad 25,76$

46 Bill Williamson

80

65 Bill Wolff

44 Bonnie Kyburz

13,40

55 Bradley Weng

74 Brandee Easter

20

71

79 Brandy Dieterle

57

47 Brenta Blevins

71 Brett Keegan

20 Brian Fitzpatrick

15,50 Brian Gaines

39 Brianne Radke

16,64 Brice Nordquist

36 Bridget Gelms

19 Bri Lafond

65 Brittany Cote

78 Bryan Jones

69

72

72

53

47

54

39

72

80

23

23 Byron Hawk

19

48 Caleb Andrew Milligan 34

36 Camden Ostrander 60

57,65 Candice Lanius $\quad 15$

59 Carleigh Davis 57

15 Caroline Dadas $\quad 19$

49 Carrie Gant $\quad 35$

35 Casey McArdle 22 
Catherine Forsa

Catheryn Jennings

Charlee Helmstetter

Charles Grimm

Charles Woods

Chelsea Slack

Chen Chen

Cheryl Ball

Chris Kamrath

Chris Lindgren

Christina Cantrill

Christina Rowell

Christopher Ritter

Christopher Stuart

Christopher Wyatt

Chrysandra Medley

Claire Lutkewitte

Cody Reimer

Collin Bjork

Courtney Cox

Courtney Werner

Courtnie Morin

Cristina Sanchez-Martin

Crystal Fodrey

Crystal VanKooten

Cynthia Davidson

Dan Frank

Daniel Anderson

Daniel Cox

Daniel Frank

Daniel Hocutt

Dànielle Nicole DeVoss

Danielle Stambler

Daniel Libertz

Daniel Liddle

Daniel Schafer

D'An Knowles Ball

David DeVine

David Giovagnoli
20 David Hochfelder

28 David Maynard

51

35 David Rieder

63 Dawn Mellinger

25,38

58 Debra Purdy

15,50 Denise Paster

17 Dennis Jerz

30 Derek Van Ittersum

36 Devon Cook

31 Devon Ralston

48 Donnie Sackey

18,38 Douglas Eyman

34 Douglas Walls

47,68 Drew Holladay

18

38

44

14

76

27

54

23

17,69

25,45

67

25

$\begin{array}{ll}42 \text { Dustin Edwards } & 72 \\ 57 \text { Edrees Nawabi } & 62\end{array}$

53 Elisa Finlay 25

47 Elizabeth Chamberlain 32

58 Elizabeth Davis

37 Elizabeth Ferguson

55

59

18 Elizabeth LaPensee $\quad 28$

33 Elizabeth Losh 29

14 Elkie Burnside 22

38 Elvira Carrizal-Dukes

73 Emily Hensley

48 Emi Stuemke

60 Eric Hamilton

16 Eric Murnane

16,40 Erika Johnson

67 Erika Romero

33

18,50

23,53

15,50

16,24

78

45

35 Erika Sparby

24

77 Erin Brock Carlson $\quad 52$

52 Erin Dittmer

80

66 Erin Kathleen Bahl 17

60 Eryn Johnson 58

72 Estee Beck 25

33 Esther Milu 37

58 Evan Cypher 
FeiFei Ma

Frank Macarthy

Gareth Young

Garrett Cummins

Gavin Johnson

Geoffrey Gimse

Greyson Sanders

Halcyon Lawrence

Haley Davis

Haley Shea Barfield

Harley Ferris

Heidi Lawrence

Heidi Naylor

Ian Golding

Ibrahim Alaswad

Jacob Greene

James Neel

Jamie Henthorn

Janine Butler
28 Jen Ware

58 Jesse Cosper

79

58 Jesse Rice-Evans $\quad 36$

54 Jessica McCaughey

18,57 Jill Belli

53

13 Jill Heney

37

38

20,71 Jim Haendiges

24 Jimmy Butts

34

34

$63 \mathrm{Jim}$ Nugent

42 Jim Purdy

22 Jody Shipka

53 Joel Bergholtz

38 John Gallagher

41 John J. Silvestro

33 John Murray

60 John Walter

33 Jon Stansell

63 Joshua Wood

46 Joyce R. Walker

Jan Rune Holmevik 15,47,50 Joy Robinson

Jason Crider

Jason Luther

Jason Markins

Jason Palmeri

Jason Stuart

Jason Tham

Jathan Day

J. Daniel Hasty

Jeaneen Canfield

Jenae Cohn

Jen Justice

Jennifer Buckner

Jennifer deWinter

Jennifer Hartshorn

Jennifer Hewerdine

Jennifer Marlow

Jennifer Miller

Jennifer Sheppard

Jennifer Warfel Juszkiewicz Kenneth Smith
60 Julia Romberger

72 Julie Bates

14,27 Julie Lindquist

17 Justin Hodgson

27,57 Kaitlin Clinnin

39 Karen Lunsford

44 Kate Birdsall

64 Kate Fedewa

26,36 Katelyn Caiati

17,27 Katherine DeLuca

38 Kathie Gossett

72 Katie Bramlett

72 Katie Manthey

49 Kati Fargo Ahern

21 Keith Dorwick

40 Kelly Moreland

30 Kem Saichaie

79
55 Justin Schumaker
25

21,55

$14,54,60$

52

33

13,73

32

30,41

54

58

$15,31,69$

55

30

21

58

71

48

55

22

22

55

24,48

75

59

48,66

77

67

20

51

74
68 
Kenton Howard

Kevin Brock

Kevin Eric DePew

Kimberly Fahle

Kirstin Bone

Knight, Aimee

Kory Ching

Kristie Ellison

Kristina Fennelly

Kristin Arola

Kristine Blair

Kristin Ravel

Kristopher Purzycki

Krystin Gollihue

Kyle Larson

Kylie Korsnack

Lacee Nisbett

Laquana Cooke

LaToya Sawyer

Laura Allen

Laura Edwards

Laura Gonzales

Laura Moeller

Laura Rosche

Lauren Brentnell

Laurence Jose

Lauren Garskie

Lauren Malone

Lauren Salisbury

Lauren Woolbright

Lee Hibbard

Lee Skallerup Bessette

Lehua Ledbetter

Les Hutchinson

Lexie Scott

Liana Clarke

Lindsey Albracht

Lisa Dooley

Lisa Dusenberry
20 Lisa Phillips

34 Liza Potts

51 Logan Middleton

47 Lourdes Fernandez

21 Lydia Wilkes

13 Lynn Reid

61 Madeleine Sorapure

18 Madison Jewell

32 Mai Xiong

23,28,30 Manea Alharbi

23,24 Marcia Bost

57,72 Marc Santos

13 Margaret Moore

36,74 Maria Novotny

31 Mark Crane

63 Martha Webber

74 Maryana Boatenreiter

31 Mary P. Sheridan

61 Mary Stewart

57 Matthew Beale

78 Matthew Duncan

15,33 Matthew Green

16,24,44 Matthew Halm

58 Matthew Jacobson

57 Matthew Kelly

55 Matt Homer

20,57 C. McAllister Williams

71 Megan Cahill-Assenza

65 Megan McIntyre

16,40 Megan McKittrick

41,63 Megan Mize

72 Meg McGuire

66 Meg Mikovits

21,31 Melanie Kill

70 Melanie Yergeau 23,39,65

61 Melissa Forbes

79

36 Melissa Green

21

53 Michael Day 21

31,74 Michael Harker 
Michael Trice

25 Robert Kachur

Michelle McMullin

52 Robert Terry

Michelle Sprouse

32 Robin Farabedian

Mike Edwards

52 Robin Wharton

Moe Folk

69 Ron Brooks

Molly Daniel

63 Ronisha Browdy

Morgan Gresham

63 Rory Lee

Morgan Read-Davidson

40 Roxanne Aftanas

63

Moriah Kirdy

73 Ruth Osorio

46

Naomi Silver

Nathan DeProspo

Nathaniel Voeller

Nicholas DeArmas

Norah Fahim

Nupoor Jalindre

Oriana Gilson

Patricia Fancher

Patricia Poblete

Patricia Sullivan

Patrick Berry

Patrick Johnson

Paul Martin

Paul Muhlhauser

Peter Brooks

Philip Choong

Rachael Lussos

Rachael Ryerson

Rachael Shapiro

Rachael Sullivan

Rachel Atherton

Rachel McCabe

Rachel Winter

Ragan Glover-Rijkse

Randy Gonzales

Rebecca Ottman

Rebecca Tarsa

Rebecca Triplett

Rebekah Shultz Colby

Rich Shivener

21,57,65 Ryan P. Shepherd

78

47 Samantha Blackmon

58

$23,24,56$

40 Samuel Stinson

54

36 Sandra Nelson

32

45,51 Santosh Khadka

55

53 Sara Austin

20

17 Sarah Baker 23

27,71 Sarah Johnson 65

52 Sarah Lozier-Laiola 24,31

39 Sarah Warren-Riley 30,53

34 Sarah Welsh 17

64 Sara Maurice Whitver 21

34,60 Savannah Block 80

65 Scott Caddy 33

20 Scott Kowalewski 80

53 Scott Reed 68

22 Sean Whelan 54

72 Sebastian Ivy 47

24 Seth Graves 36

45 Shane Combs 58

79 Shannon Butts 60

18,50 Shauna Chung $\quad 15,50$

36 Shelley Lloyd 50

77 Shelley Rodrigo $\quad 47$

79 Shelly Lloyd 15

33 Simon Cruz 28

70 Skyler Schack $\quad 35$

53 Stacy Wittstock 61

19 Stan Harrison 77 
Stephanie Hedge 50

Stephanie Hilliard 69

Stephanie Vie 40

Stephanie Weaver 24

Stephanie West-Puckett 48

Stephen Boakye 45

Stephen McElroy $\quad 51$

Stephen Quigley 60

Steve Benninghoff $\quad 80$

Steve Holmes 59

Steve Krause $\quad 37$

Steven Smith 38

Sushil K. Oswal 46

Suzanne Sink 67

Sweta Baniya $\quad 31,70$

Sydney Bufkin $\quad 67$

Theresa Evans $\quad 77$

Thomas Geary 59

Thomas Javier Castillo 15

Tialitha Macklin 61

Tiffany Carter 27

Tim Lockridge 76

Timothy Laquintano $\quad 59$

Tina Arduini 77

Tracey Hayes 62

Trenia Napier 18

Veronica Garrison-Joyner 61

Victor Del Hierro 37

Victoria Houser $\quad 15,47,50$

Vyshali Manivannan 72,78

Wendi Sierra $17,42,48,69$

Wenqi Cui 66

Willa Murphy 49

Will Penman 17

Zach Whalen 72 
gayle morris sweetland

digital rhetoric collaborative

The Sweetland Digital Rhetoric Collaborative - a collaboration of the Gayle Morris Sweetland Center for Writing, the University of Michigan Press, and Michigan Publishing - is both a book series and a community web space by and for scholars and teachers working in computers and writing and digital rhetoric.

我 digitalrhetoriccollaborative.org $\operatorname{IfS}$ SweetlandDRC

Want to get involved with the Digital Rhetoric Collaborative community?

Apply to be a DRC Graduate Student Fellow • Contribute to a Blog Carnival

Review a conference session - Submit a proposal to the DRC Book Prize

Add to the DRC Wiki • Use DRC materials in your classroom

Learn about all of these opportunities, and more, on the DRC website!

VIIISA SWWEETLAND CENTER FOR WRITING

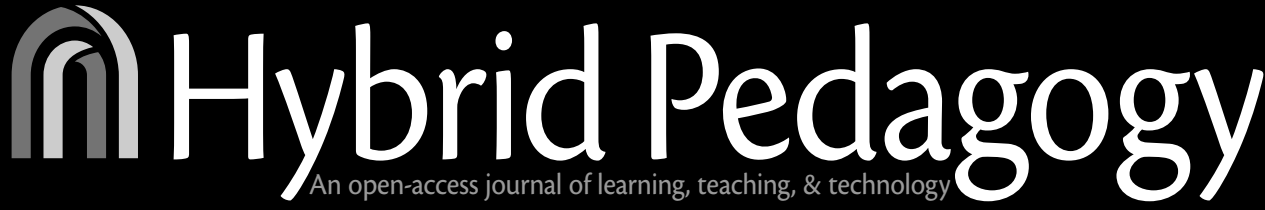

ARTICLES ADVOCATE FOR:

OUR PROCESS FEATURES:

- Student agency

- Critical pedagogy

- Marginalized voices

- Reflective praxis
- Radical openness

- Iterative, collaborative, conversation-driven peer review

\section{Visit us online or chat in the Johnson Center!}
$\mathcal{S}$ hybridpedagogy.org
f hybridped
Y@hybridped 


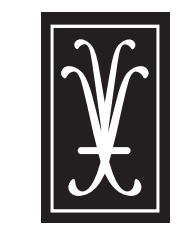

FIUNTAINHEAD

PRESS

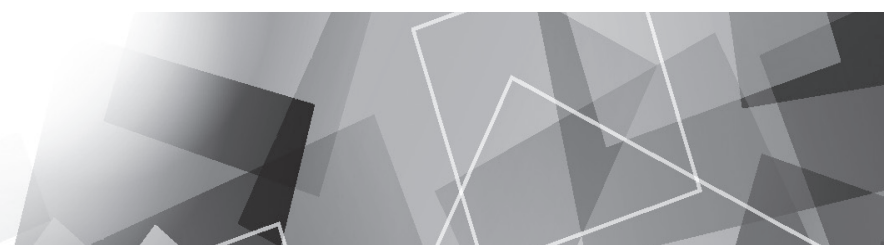

Fiercely Independent

Fountainhead Press is a unique, independent publisher concerned with producing innovative, lowcost textbooks and custom products. Our mission focuses on working with universities to create ideal, program-specific texts. Importantly, we prioritize sustainable printing practices, using only FSC certified printers and printing on $30 \%$ post-consumer waste, recycled paper.

\section{Fountainhead Press content represents the most recent conversations in teaching Composition.}
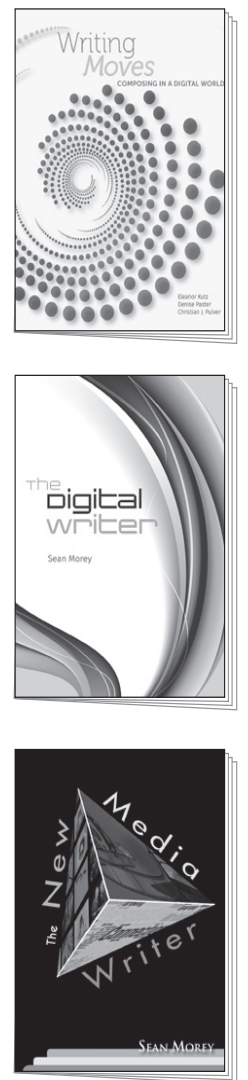

Writing Moves is a comprehensive first-year guide to writing effectively in and across a range of private, public, and academic communities in a digital world. Each chapter details writing strategies (moves) for inventing, drafting, revising, publishing, and circulating that are specific to different contexts for writing.

Authors: Eleanor Kutz, Denise Paster, Christian J. Pulver

978-1-68036-392-0

The Digital Writer is an introduction to writing that extends traditional concepts of argumentation and rhetoric to include an emphasis on how digital rhetorics and technologies transform writing practices in students' everyday lives as well as their academic and professional careers.

Author: Sean Morey

978-1-68036-354-8

The New Media Writer invites students to become producers, rather than simply consumers, of new media, instructing them in how to interpret, plan, compose, revise, and distribute their work utilizing digital technologies

Author: Sean Morey

978-1-59871-780-8 
Eli Review is a peer learning app that helps instructors build a culture of feedback.

Eli codes reciprocity as a key feature of a feedback-rich culture.

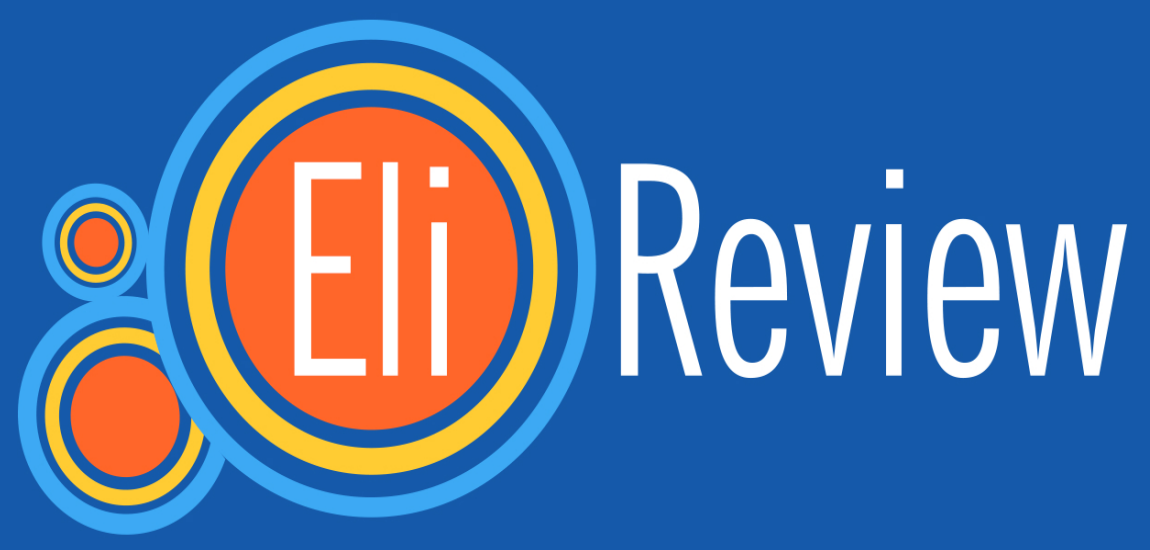

We're playing with methods to represent reciprocity and need your input. Read about it and vote for the best graph:

\section{goo.gl/op750x}




\section{Rhetoric and Professional Writing}

\section{$\mathrm{PhD}$ in English}

Concentration areas include Rhetoric and Composition Professional Writing Digital Studies

Teaching assistantships are available. Professional development and teacher training in composition, technical writing, writing centers, and writing program administration.

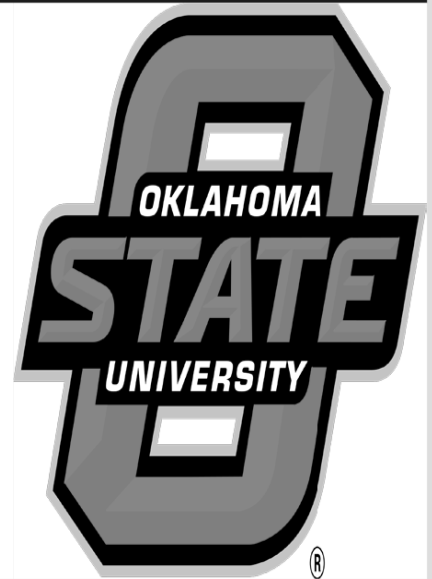

find more online english.okstate.edu

\section{A Splendid Wake}

Archiving the Poets and Poetry of the DC Area

Annual Spring Equinox Program Summer Solstice PopUp Poetry Blog

$$
\text { Visit Our Wiki: }
$$

https://wikis.library.g wu.edu/dcpoetry/

Read ( and contribute to) our Blog https://splendidwake.blogspot.com

Interested in volunteering?

Contact: asplendidwake (a) 9 mail.com 


\section{TEXAS STATE UNIVERSITY \\ MA RHETORIC \& COMPOSITION}

- Explore minority rhetorics, digital literacies, writing centers, writing and empathy, and more.

- Work with nationally-recognized faculty

"My experience in the program has been

- Teach writing in high schools and universities

- Develop and lead writing initiatives

- Write professionally

- Pursue the PhD in Rhetoric and Composition

invaluabe to me as a composition instructor and to my development as a

Ph.D.student." Casie Moreland

Graduate Assistantships, Scholarships, and Financial Aid available

CONTACT: MARC@TXSTATE.EDU 512-245-7684 MARC.ENGLISII.TXSTATE.EDU

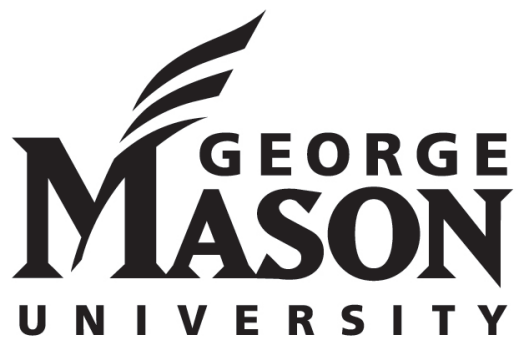

University Libraries 

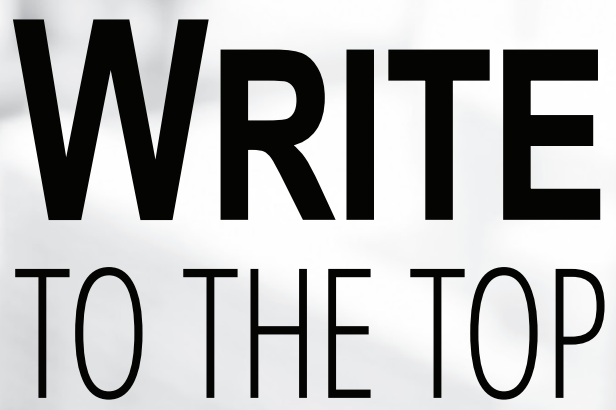

\section{Earn a Professional Writing master's degree or graduate certificate online from ODU.}

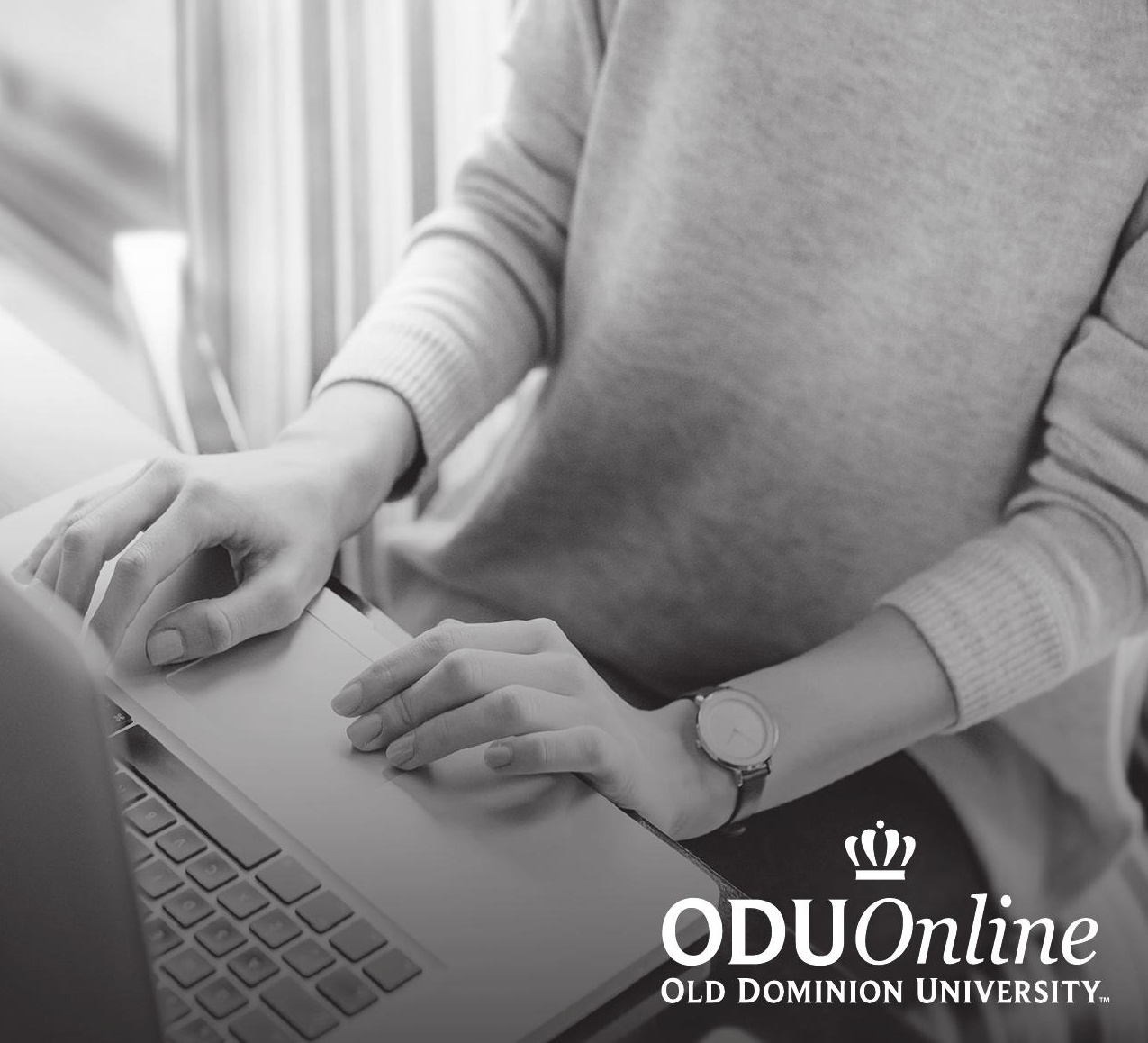

Contact us today to learn more: ONLINE.ODU.EDU/GRAD-WRITE 
